\title{
Tropical and mid-latitude teleconnections interacting with the Indian summer monsoon rainfall: a theory-guided causal effect network approach
}

\author{
Giorgia Di Capua ${ }^{1,2}$, Marlene Kretschmer ${ }^{1, a}$, Reik V. Donner ${ }^{1,3}$, Bart van den Hurk ${ }^{2,4}$, Ramesh Vellore ${ }^{5}$, \\ Raghavan Krishnan ${ }^{5}$, and Dim Coumou ${ }^{1,2}$ \\ ${ }^{1}$ Potsdam Institute for Climate Impact Research, Member of the Leibniz Association, Potsdam, Germany \\ ${ }^{2}$ Institute for Environmental Studies, VU University of Amsterdam, Amsterdam, the Netherlands \\ ${ }^{3}$ Department of Water, Environment, Construction and Safety, Magdeburg-Stendal University \\ of Applied Sciences, Magdeburg, Germany \\ ${ }^{4}$ Deltares, Delft, the Netherlands \\ ${ }^{5}$ Centre for Climate Change Research, Indian Institute for Tropical Meteorology, Pune, India \\ ${ }^{a}$ currently at: Department of Meteorology, University of Reading, Reading, UK
}

Correspondence: Giorgia Di Capua (dicapua@pik-potsdam.de)

Received: 23 July 2019 - Discussion started: 5 August 2019

Accepted: 30 November 2019 - Published: 17 January 2020

\begin{abstract}
The alternation of active and break phases in Indian summer monsoon (ISM) rainfall at intraseasonal timescales characterizes each ISM season. Both tropical and mid-latitude drivers influence this intraseasonal ISM variability. The circumglobal teleconnection observed in boreal summer drives intraseasonal variability across the mid-latitudes, and a two-way interaction between the ISM and the circumglobal teleconnection pattern has been hypothesized. We use causal discovery algorithms to test the ISM circumglobal teleconnection hypothesis in a causal framework. A robust causal link from the circumglobal teleconnection pattern and the North Atlantic region to ISM rainfall is identified, and we estimate the normalized causal effect (CE) of this link to be about 0.2 (a 1 standard deviation shift in the circumglobal teleconnection causes a 0.2 standard deviation shift in the ISM rainfall 1 week later). The ISM rainfall feeds back on the circumglobal teleconnection pattern, however weakly. Moreover, we identify a negative feedback between strong updraft located over India and the Bay of Bengal and the ISM rainfall acting at a biweekly timescale, with enhanced ISM rainfall following strong updraft by 1 week. This mechanism is possibly related to the boreal summer intraseasonal oscillation. The updraft has the strongest CE of 0.5 , while the Madden-Julian oscillation variability has a CE of $0.2-0.3$. Our results show that most of the ISM variability on weekly timescales comes from these tropical drivers, though the mid-latitude teleconnection also exerts a substantial influence. Identifying these local and remote drivers paves the way for improved subseasonal forecasts.
\end{abstract}

\section{Introduction}

The Indian summer monsoon (ISM) is crucial for Indian society, which receives $75 \%$ of its total annual rainfall during the summer months June through September (JJAS). The ISM rainfall variability at intraseasonal timescales is characterized by periods of enhanced and reduced rainfall activity over the monsoon core region of central India. These periods are usually referred to as active (wet) and break (dry) phases, respectively, and have a duration that spans from a few days up to 3 weeks. Prolonged active and break spells in the ISM can lead to floods or droughts and consequently have severe socio-economic implications for the Indian subcontinent. A salient semi-permanent feature of the ISM is the "monsoon trough" (MT), which manifests as a low-pressure zone extending from north-western India into the Gangetic plains 
and the Bay of Bengal (Rao, 1976; Krishnamurti and Sugi, 1987; Choudhury and Krishnan, 2011). The rainfall amount over the MT region is generally used to define dry and wet spells within the ISM season (Krishnan et al., 2000; Gadgil and Joseph, 2003). The position and strength of the MT significantly influence the spatial distribution of monsoon precipitation and associated agricultural productivity on the Indian subcontinent, and the internal dynamics of the ISM circulation itself provide a first mechanism for intraseasonal rainfall variability (Pathak et al., 2017).

The land-sea temperature difference and the midtropospheric thermal forcing over the Tibetan Plateau are the prime drivers for the monsoon circulation (Yanai and $\mathrm{Wu}$, 2006). Ascending motions over the Indian subcontinent enhance the northward air flux from the ocean toward the land, thereby bringing moisture from the ocean and fuelling rainfall. The latent heat released by strong convective rainfall is important for sustaining the ISM circulation (Levermann et al., 2009). However, it has two opposing effects: on the one hand, the latent heat release in the early stage of an active phase enhances ascending motions by heating the middle to lower troposphere (Levermann et al., 2009). On the other hand, latent heat release that propagates upward and heats the upper layers of the air column tends to increase the static stability and inhibit further ascending motions (Saha et al., 2012). Also, rainy weather and cloudy skies can have a cooling effect on the surface, which tends to suppress convection (Krishnamurti and Bhalme, 1976). While this thermodynamic perspective is useful to understand the quasi-biweekly variations of the ISM elements locally, the spatio-temporal variations in the evolution of active and break phases over the Indian monsoon region are known to involve interactions between the wind anomalies and the northward propagation of the major rain band anomalies of the boreal summer intraseasonal oscillation (BSISO) (Wang et al., 2006; Chattopadhyay et al., 2009; Shige et al., 2017).

The boreal summer intraseasonal oscillation represents a characteristic feature of the atmospheric circulation over the northern Indian Ocean and South Asia (Goswami and Ajaya Mohan, 2001; Saha et al., 2012; Suhas et al., 2012). The BSISO is identified as a rainfall band that stretches from the Indian subcontinent to the Maritime Continent, featuring a north-west-south-east tilt and propagating north-eastward from the equatorial Indian Ocean towards South East Asia with a timescale of about 1 month (Wang et al., 2006; Webster and Lawrence, 2002). The BSISO can influence the oscillation between break and active phases typical for the ISM intraseasonal variability, with favourable conditions for the initiation of an active phase when the BSISO rainfall band reaches the Indian subcontinent during its north-eastward propagation (Goswami and Ajaya Mohan, 2001; Suhas et al., 2012). Krishnan et al. (2000) hypothesized that the triggering of Rossby waves by suppressed convection over the Bay of Bengal initiates ISM breaks through the north-west propagation of high-pressure anomalies from the central Bay of Bengal into north-west India. They noted that the initiation of suppressed convection and anticyclonic anomalies over the equatorial Indian Ocean and central Bay of Bengal occurred a week prior to the commencement of a monsoon break over India, followed by the traversing of suppressed anomalies from the central Bay of Bengal to north-west India in about 2-3 d.

At intraseasonal timescales, the Madden-Julian oscillation (MJO), which governs the intraseasonal tropical climate variability operating at a 30-90 d timescale, represents an important tropical driver of the ISM intraseasonal variability (Zhang, 2005). The MJO consists of a transient region of strong convective motions and enhanced precipitation, which propagates eastward from the tropical Indian Ocean to the tropical western Pacific. Normally, only one area of strong convective motions related to the MJO is present in these regions. The MJO influences the ISM system with enhanced convective rainfall activity during active MJO phases and negative rainfall anomalies during suppressed MJO phases (Anandh et al., 2018; Mishra et al., 2017; Pai et al., 2011). However, during boreal summer, the MJO strength is reduced compared to boreal winter, and both the MJO and the BSISO propagation and phases can be well described by the outgoing longwave radiation MJO index (OMI) (Wang et al., 2018).

Next to tropical drivers, mid-latitude circulation, the North Atlantic variability and mid-latitude wave trains have been proposed to modulate the occurrence of active and break phases of the ISM (Kripalani et al., 1997; Ding and Wang, 2005, 2007). A circumglobal teleconnection pattern characterized by wave number 5 has been associated with seasonal and monthly rainfall and surface air temperature anomalies across the Northern Hemisphere in summer (Ding and Wang, 2005). One way to identify this circumglobal teleconnection pattern is via point-correlation maps of the $200 \mathrm{hPa}$ geopotential height with a location directly east of the Caspian Sea. A two-way interaction between the ISM circulation system and the circumglobal teleconnection pattern has been hypothesized: while the diabatic heat sources associated with ISM convection can reinforce the circumglobal teleconnection pattern propagating downstream (i.e. moving from west to east following the mid-latitude westerlies), the circumglobal teleconnection pattern itself may modulate the ISM rainfall, with enhanced rainfall associated with the positive phase of the circumglobal teleconnection pattern (Ding and Wang, 2005). The circumglobal teleconnection pattern also shows inter-decadal variations, with a general weakening of its major centres of action over the last 3 decades, which has been attributed to weakening of the ISM precipitation and to the relation of the ISM with the El Niño-Southern Oscillation (ENSO) (Wang et al., 2012). Seasonal forecast models, e.g. simulations based on seasonal forecasts from the European Centre for Medium-Range Weather Forecasts (ECMWF), tend to have difficulties reproducing this pattern correctly: the circumglobal teleconnection pattern is too 
weak in models, and one of the possible causes could be an interaction with the north-western India rainfall that is too weak (Beverley et al., 2019).

The latent heat released via strong convection in the ISM region has also been shown to influence regions which are located upstream (i.e. eastward). The so-called monsoondesert mechanism involves long Rossby waves to the west of the ISM region generated by ISM latent heating. These waves enhance the downward flow over the eastern Mediterranean and north-eastern Sahara, suppressing precipitation in these dry regions (Rodwell and Hoskins, 1996). A subset of CMIP5 models is able to capture this mechanism (Cherchi et al., 2014), and CMIP5 scenarios for the 21st century project increased ISM precipitation despite a decrease in the strength of the ISM circulation. Thus, the monsoon-desert mechanism could contribute to drying and warming trends projected for the eastern Mediterranean region, exacerbating the desiccation conditions in these regions (Cherchi et al., 2016).

The variability of sea surface temperatures (SSTs) and mid-tropospheric variables in the North Atlantic region has been shown to influence the ISM at a wide range of timescales. At inter-decadal and interannual timescales, SSTs related to the Atlantic Multi-decadal Oscillation (AMO) index have been shown to modulate the strength of the ISM by an atmospheric bridge involving the North Atlantic Oscillation (NAO) index: positive (negative) NAO phases alter westerly winds and associated storm tracks in the North Atlantic-European area and modify tropospheric temperatures over Eurasia, thus enhancing (weakening) the strength of the ISM rainfall (Goswami et al., 2006). At intraseasonal timescales, a wave train originating from the north-eastern Atlantic and propagating along an arch-shaped trajectory into central Asia may influence the intraseasonal variability of the ISM and modulate the intensity of the northern ISM rainfall at a biweekly timescale, linking the latter with mid-latitude circulation features (Ding and Wang, 2007; Krishnan et al., 2009). An important feature of this wave train is the $200 \mathrm{hPa}$ Central Asian High, located to the east of the Caspian Sea, i.e. over the same region used to define the circumglobal teleconnection pattern, which may trigger positive rainfall anomalies over the northern ISM region by modifying the easterly vertical shear that drives the ISM circulation and its related effect on moist dynamic instability in the ISM region. Thus, this wave train generated in the North Atlantic might aid in modulating the alternating active and break conditions over central India (Ding and Wang, 2007; Krishnan et al., 2009; Saeed et al., 2011). A positive feedback mechanism between the northern ISM and the Central Asian High has also been hypothesized, with enhanced ISM precipitation acting to reinforce the positive anomaly in the Central Asian High via a Rossby wave response related to the ISM heating source (Ding and Wang, 2007).

Lagged correlation and regression analyses have been commonly used to assess the relationship between two or more climate variables (Ding and Wang, 2005; Lau and Kim, 2011; Vellore et al., 2014). Such an analysis is useful as it gives first information on the association of two or more variables, but it can easily lead to erroneous interpretations. For instance, two non-causally related variables can appear significantly correlated due to strong autocorrelation and/or common driver effects (McGraw and Barnes, 2018; Runge et al., 2014). In lead-lag regression analyses, the causal direction is assumed to be from the variable that leads to the variable that lags. However, in complex dynamical systems there is often no solid basis for such assumptions. For example, linear regressions alone would suggest that surface temperatures over North and South America lead ENSO variability, while the opposite causal relationship is generally accepted (McGraw and Barnes, 2018). When controlling for the autocorrelation of ENSO, this spurious correlation vanishes (McGraw and Barnes, 2018). However, due to the numerous (possible) linkages in the climate system, it is usually not obvious which variables to control for when studying the dependence of two processes.

To overcome these issues, causal discovery algorithms such as causal effect networks (CENs) have been recently developed and subsequently applied to gain insights into the physical links of the climate system (Kretschmer et al., 2016, 2018; Runge et al., 2015, 2019). For a given set of time series, a CEN reconstructs the likely underlying causal structure by iteratively testing for conditional independent relationships among the input time series. CENs have been applied to the study of stratospheric polar vortex variability (Kretschmer et al., 2016, 2018), the multi-decadal North Atlantic overturning circulation (Schleussner et al., 2014), the intraseasonal stratosphere-troposphere coupling in the Southern Hemisphere (Saggioro and Shepherd, 2019), and the causal interactions between the ISM, the Silk Road pattern and the monsoon-desert mechanism (Stephan et al., 2019). Although shown to be a useful statistical tool to study teleconnection pathways, a successful application of CEN requires (such as any data-driven method) expert knowledge of the underlying physical processes, including the relevant variables, timescales and temporal resolution (Runge, 2018).

Here we study the two-way interactions of tropical and mid-latitude regions with the ISM by applying such a theoryguided causal effect analysis. First, we assess whether the connection between the ISM and the mid-latitude wave trains can be considered causal in one or both directions. Next, we quantify the relative causal effect of tropical, mid-latitude and internal drivers on the ISM. The remainder of this paper is organized as follows: Sect. 2 describes the data and methods that have been applied. Section 3 presents the results obtained by applying causal discovery tools to the analysis of the ISM mid-latitude and tropical drivers. In Sect. 4, these results are discussed in the context of the existing literature and our conclusions are presented. 


\section{Data and methods}

\subsection{Data}

We define the monsoon trough (MT) region as the regions between $18-25^{\circ} \mathrm{N}$ and $75-88^{\circ} \mathrm{E}$. We analyse weekly rainfall averages over these region from the CPC-NCEP $\left(0.25^{\circ} \times 0.25^{\circ}\right)$ observational gridded global rainfall dataset over the period 1979-2016 (Chen et al., 2008) and from the Pai et al. $(2015)\left(0.25^{\circ} \times 0.25^{\circ}\right)$ observational gridded Indian rainfall dataset over the period 1979-2017 (Pai et al., 2015). In the remainder of this paper, we will mainly focus on the results obtained for the latter dataset, while those for the former are provided as parts of the Supplement. Using data taken from the ERA-Interim reanalysis (Dee et al., 2011) for the period 1979-2017, precursor regions are calculated from global weekly averaged gridded $\left(1.5^{\circ} \times 1.5^{\circ}\right)$ fields including outgoing longwave radiation (OLR) at the top of the atmosphere, vertical velocity at $500 \mathrm{hPa}$ (W500) and geopotential height at $200 \mathrm{hPa}$ (Z200). The NAO weekly index is obtained by averaging daily data from NOAA (available at ftp://ftp.cpc.ncep.noaa.gov/ cwlinks/norm.daily.nao.index.b500101.current.ascii, last access: 13 January 2020). To identify MJO phases, we use the OLR MJO index (OMI) provided by NOAA (https:// www.esrl.noaa.gov/psd/mjo/mjoindex/, last access: 13 January 2020). This metric features the first and second principal components obtained by the empirical orthogonal function (EOF) analysis of OLR in the tropical belt (between $30^{\circ} \mathrm{N}$ and $30^{\circ} \mathrm{S}$ ) filtered to remove influences outside the MJO timescale (30-90 d). OMI PC2 corresponds to the first principal component of the real-time multivariate MJO index (RMM1), which is widely used in the literature (Wheeler and Hendon, 2004; Pai et al., 2011; Kiladis et al., 2014). Moreover, the OMI has also been proven useful in describing the BSISO behaviour, which is relevant for the ISM break and active phases in summer (Wang et al., 2018). All time series of MT rainfall, Z200 and all datasets analysed in this work are detrended and anomalies are calculated at weekly time steps. Thus, both the climatological and seasonal cycles are removed. Since the interannual variability may affect the analysis, we follow the approach proposed by Ding and Wang (2007) and filter the data by removing from each JJAS season its seasonal average.

\subsection{Causal effect networks}

We apply causal effect networks (CENs) and the responseguided causal precursor detection (RG-CPD) tool, two recently developed applications of the so-called Peter and Clark momentary conditional independence (PC-MCI) algorithm (Spirtes et al., 2000; Runge et al., 2014, 2019). A CEN detects and visualizes the causal relationships among a set of univariate time series of variables (here referred to as actors; Kretschmer et al., 2016). The network is constructed using the PC-MCI algorithm, which is a causal discovery algorithm able to distinguish between spurious and true causal links for different time lags of interest (Runge, 2018). The term "causal" rests on several assumptions (Spirtes et al., 2000; Runge, 2018). Here, it should be understood as causal relative to the set of analysed precursors, meaning that the identified causal links are valid relative to the selected set of actors. Adding additional actors may change the structure of the causal network. It is therefore crucial to combine CEN with theoretical domain knowledge (i.e. our "theory-guided causal discovery analysis" approach). Other important assumptions are the stationarity of time series and near-linear interactions between actors; i.e. the selected actors should have a linear behaviour at least in a first-order approximation.

The PC-MCI algorithm is a two-step algorithm based on a modified version of the Peter and Clark (PC) algorithm (Spirtes et al., 2000; Runge et al., 2014, 2019). In the first step (the PC step), the relevant conditions for each variable are identified by iterative independence testing. The following MCI step tests whether the link between two actors can be considered causal. The false discovery rate (FDR) approach, as described by Benjamini and Hochberg, is applied to correct for inflated $p$ values due to multiple significance testing (Benjamini and Hochberg, 1995; Benjamini and Yekutieli, 2001). Each step is further described below.

In a variable set $P$ containing $n$ univariate detrended anomaly time series (the actors), the PC step identifies the causal parents of each $i$ th element in $P$ among all the remaining elements in $P$. First, the PC algorithm calculates plain correlations between each $i$ th actor in $P$ and all the remaining elements at a certain time lag $\tau$. Those actors that significantly correlate with the $i$ th actor form the set of its potential parents $P_{i}^{0}$ at lag $\tau$. Then, partial correlations between the $i$ th actor and each element $j$ th in $P_{i}^{0}($ where $i \neq j$ ), are calculated, conditioning first on one condition, i.e. the first $k$ th actor in $P_{i}^{0}$ that has the strongest correlation with the $i$ th actor and $i \neq j \neq k$. If $x, y$ and $z$ are elements in $P$, the partial correlation between $x$ and $y$ conditioned on $z$ is calculated by first performing linear regressions of $x$ on $z$ and of $y$ on $z$ and then calculating the correlation between the residuals. If the resulting partial correlation between $x$ and $y$ is still significant at a certain significance threshold $\alpha, x$ and $y$ are said to be conditionally dependent given variable $z$; i.e. the correlation between $x$ and $y$ cannot be (exclusively) explained by the influence of variable $z$. When the opposite happens, the link is spurious and therefore filtered out, and $x$ and $y$ are called conditionally independent. This process leads to a reduced set of parents $P_{i}^{1}$. In the next step, the process is repeated but conditioning on two conditions, i.e. calculating the linear regression on a set of two actors, leading to a second set of parents $P_{i}^{2}$. The algorithm converges when the number of causal parents contained in $P_{i}^{m}$ is equal to or greater than the number of conditions needed to calculate the next partial correlation. At the end of the PC step, each element in $P$ has its own 
set of parents, which then enters the MCI step. In the MCI step, the partial correlation between an actor and its initial set of potential parents is calculated again but conditioned simultaneously on both the set of parents of the $i$ th actor and the sets of parents of each of the parents of the $i$ th actor. Those parents that pass the MCI test will then form the final set of parents for the $i$ th actor (Runge et al., 2019). A numerical example of these steps is given in the Supplement, together with the values for each parameter used for PCMCI. For this study, the Python package Tigramite version 3.0 is used (https://github.com/jakobrunge/tigramite_old, last access: 13 January 2020).

The causal links detected via the PC-MCI algorithm are visualized in terms of a causal effect network (CEN). Each CEN is composed of circles representing the various actors and of arrows, with the colour indicating the strength and the arrow the direction of the detected causal links. The strength is expressed by its associated path coefficient, defined following Runge et al. (2015) as the "expected change in $X^{j}$ (in units of its standard deviation [s.d.] and relative to the unperturbed regime) at time $t$ if $X^{i}$ was perturbed at time $t-\tau$ by a one s.d. delta peak". To give an example, a path coefficient of 0.5 means that a change in the causal parent of 1 standard deviation (SD) corresponds to a change of $0.5 \mathrm{SD}$ in the analysed actor. Here, due to the fact that only lags at $\tau=1$ are accounted for, the path coefficients also correspond to the total causal effect (CE). The path coefficient of each variable on itself is here referred to as the autocorrelation path coefficient. This should not be confused with the usual definition of the lag-1 autocorrelation coefficient. The autocorrelation path coefficient is the same as the path coefficient with $i=j$, and it represents the causal influence of an actor on itself.

\subsection{Response-guided causal precursor detection}

RG-CPD identifies the causal precursors of a response variable based on multivariate gridded observational data (Kretschmer et al., 2017; Di Capua et al., 2019). It combines a response-guided detection step (Bello et al., 2015) with the PC-MCI causal discovery step (Spirtes et al., 2000; Runge et al., 2014, 2015, 2019). Without requiring an a priori definition of the possible precursors, RG-CPD searches for spatially contiguous regions in multivariate gridded data that are significantly correlated with a variable of interest (i.e. the response variable) at a given lag and then detects causal precursors by filtering out spurious links due to common drivers, autocorrelation effects or indirect links. Using correlation maps, an initial set of precursors is identified in relevant meteorological fields by finding regions in which the recorded variability precedes changes in the response variable at some lead time. Correlation values are calculated with a two-sided $p$ value for a hypothesis test, whose null hypothesis is that there is no correlation, using the Wald test with a $t$ distribution of the test statistic. All $p$ values are corrected using the Benjamini and Hochberg false discovery rate
(FDR) approach to address the variance inflation due to serial correlations (Benjamini and Hochberg, 1995; Benjamini and Yekutieli, 2001). Then, adjacent grid points with a significant correlation of the same sign at a level of $\alpha=0.05$ are spatially averaged to create single one-dimensional time series, characterizing the dynamics of the considered field in the socalled precursor region (Wilks, 2016; Willink et al., 2017). In the second step, PC-MCI identifies the set of causal precursors for the response variable. The results present those precursor regions on a global map that are identified to be causally linked with the response variable (here, the MT rainfall).

\section{Results}

\subsection{Causal testing of the two-way ISM circumglobal teleconnection mechanism and the influence of NAO}

First, we assess whether the two-way interaction between the circumglobal teleconnection pattern (that characterizes the boreal summer circulation) and the MT rainfall, as hypothesized by Ding and Wang (2005, hereafter DW2005), is reproduced using our CEN analysis. We will refer to this theory as the monsoon-circumglobal teleconnection mechanism. We also analyse the influence of the North Atlantic on the MT rainfall, as hypothesized by Ding and Wang (2007, hereafter DW2007).

Figure 1a and $\mathrm{b}$ show the JJAS climatology and the SD of weekly ISM rainfall from the Pai et al. (2015) dataset for the period 1979-2017. We average the rainfall over the MT region and identify a univariate time series, which represents the weekly variation of the ISM during JJAS over the MT region (Fig. 1c). This time series contains 18 weeks for each of the 39 analysed years, with each year starting on 27 May. The analysis of the MT rainfall starts on the third week (10 June) for a total of $167 \mathrm{~d}$ time slots per year. Skipping the two first time steps (weeks) of each monsoon season is necessary since they allow for the detection of lagged relationships, and the PC-MCI algorithm requires adding twice the maximum time lag explored (here a maximum lag of 1 week is chosen). Information from the previous year does not interfere with the following year. The weekly timescale is considered to represent the relevant interaction between ISM rainfall and Northern Hemisphere atmospheric circulation at intraseasonal timescales (Krishnamurti and Bhalme, 1976; Ding and Wang, 2007; Vellore et al., 2014). Moreover, a weekly timescale is also adequate to represent the propagation of different BSISO phases and the switch between active and break phases of the ISM (Goswami and Ajaya Mohan, 2001).

To analyse the major mode of Z200 variability in the Northern Hemisphere mid-latitudes, following DW2005, we calculate the first and second empirical orthogonal functions (EOFs) of weekly averaged Z200 fields over the Northern 

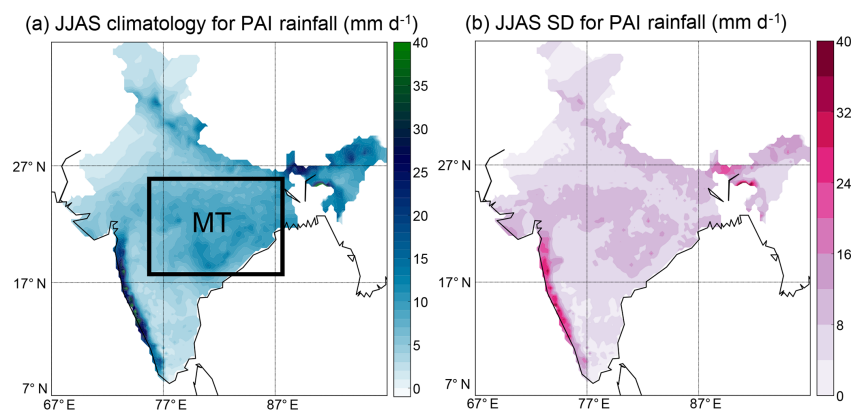

(c) JJAS weekly anomalies for PAI rainfall - 1979-2017 (mm d-1)

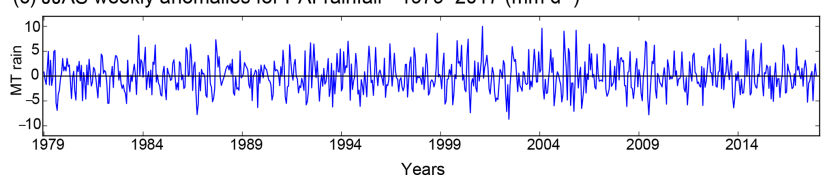

Figure 1. Rainfall climatology over the study area. (a) JJAS rainfall climatology over the 1979-2017 period from the Pai et al. (2015) dataset. The black box identifies the MT region. (b) Standard deviation (SD) of weekly JJAS rainfall over the 1979-2017 period from the Pai et al. (2015) dataset. (c) Time series of weekly MT JJAS rainfall over the period 1979-2017; each year contains 18 weeks, with the first week starting on 27 May.

Hemisphere $\left(0-90^{\circ} \mathrm{N}, 0-360^{\circ} \mathrm{E}\right)$ for the summer months coinciding with the ISM season (June to September, weeks 21 to 38). Figure 2a and $\mathrm{b}$ show these first and second EOFs. EOF1 represents the dominant component of intraseasonal variability of the Z200 field and qualitatively resembles the SD of Z200 (see Fig. S1 in the Supplement). EOF2 represents the second dominant pattern of intraseasonal variability of the Z200 field. However, EOF1 and EOF2 respectively explain only $6.4 \%$ and $6.2 \%$ of the intraseasonal variability, i.e. after removing mean annual cycle and interannual variability. The first five EOFs together explain $28.5 \%$ of the total variability. These low values are not surprising if we consider that the mean annual cycle and interannual variability have been removed, thus leaving only the disturbances from the year-specific mean state. We apply a test for pronounced separation of EOFs following North et al. (1982). This test is based on the eigenvalues of the EOF analysis and provides a rule of thumb to determine whether two EOFs are degenerate, i.e. "indistinguishable between their uncertainties" (for further details, see North et al., 1982, and Hannachi et al., 2007). The test shows that the first three EOFs are not well separated mutually, while EOF1 and EOF2 are well separated from EOF4 and EOF5 (see the Supplement, Fig. S2). Similarly, DW2007 also found a twin EOF mode in their study, although their work focuses on the Eurasian sector only. However, by design EOFs do not necessarily reflect physical patterns (irrespective of whether the individual EOFs are separable or not). They only capture dominant patterns of variability, and here EOF2 is useful since it resembles the wave pattern in the correlation map and thus likely
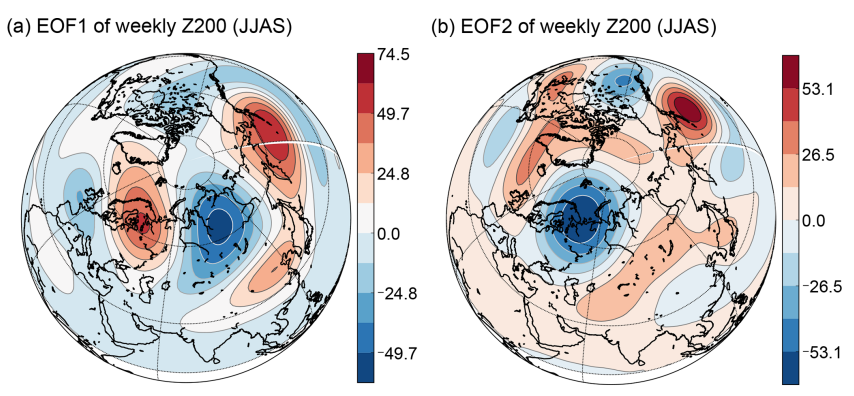

(c) Lag - 1 correlation of Z200 with MT rain

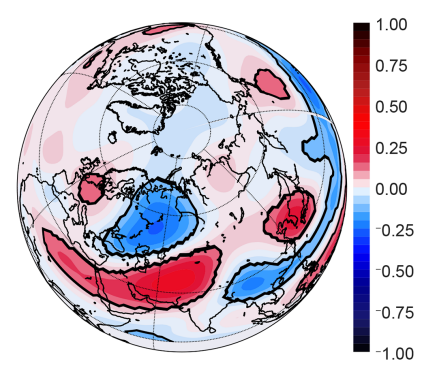

(e) T anomalies associated with CGTI (K)

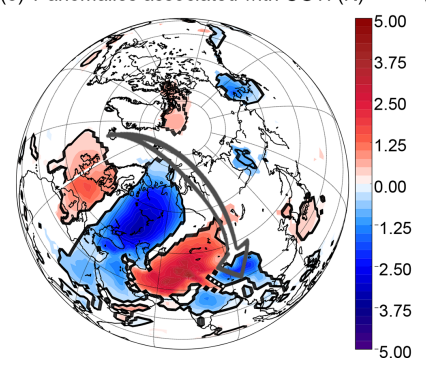

(d) Lag-0 correlation of Z200 with CGT

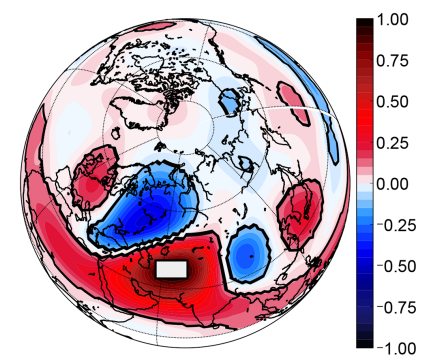

(f) P anomalies associated with CGTI $\left(\mathrm{mm} \mathrm{d}^{-1}\right)$

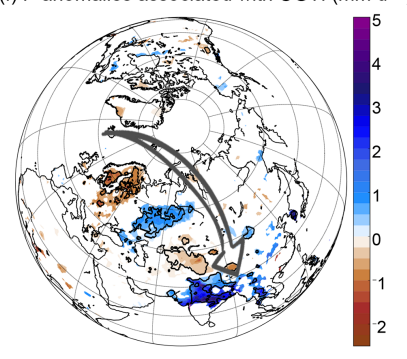

Figure 2. Mid-latitude variability associated with the ISM. $(\mathbf{a}, \mathbf{b}) \mathrm{EOF} 1$ and EOF2 expressed as covariance for the JJAS weekly Z200 field in the Northern Hemisphere $\left(0-90^{\circ} \mathrm{N}, 0-360^{\circ} \mathrm{E}\right)$ for the period 1979-2017. (c) Correlation between weekly MT rainfall (lag =0) and Z200 (lag = 1 week). (d) The CGTI region (white box) and the correlation between CGTI and Z200 (both at lag $=0$ ), which forms the circumglobal teleconnection pattern. In panels (c) and (d), correlation coefficients with a $p$ value of $p<0.05$ (accounting for the effect of serial correlations) are shown by black contours. (e) Composite temperature difference between

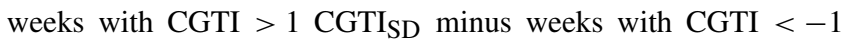

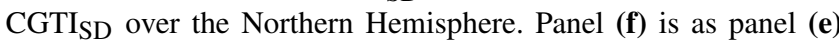
but for rainfall anomalies from the CPC-NCEP dataset (as rainfall data for the Pai et al., 2015, dataset are available over India only) for the period 1979-2017. In panels (e) and (f), anomalies with a $p$ value of $p<0.05$ (accounting for the effect of serial correlations) are shown by black contours, while grid points which are found significant only with non-corrected $p$ values are shaded.

results from the physics related to the circumglobal teleconnection pattern. In general, we cannot a priori exclude an influence of EOF1 on the analysed system (while an influence from EOF2 is expected). Therefore, we will test whether this is the case in the following part of this subsection. 
DW2005 define the ISM circumglobal teleconnection mechanism at an interannual and monthly timescale, and DW2007 use daily data (after removing the interannual variability) to analyse the influence of the Eurasian wave train initiated from the North Atlantic on the north-central Indian rainfall. Thus, first we need to show that the definition of the circumglobal teleconnection pattern as in DW2005 also applies meaningfully at weekly timescales with the interannual variability filtered out. Figure $2 \mathrm{c}$ shows the spatial correlation structure of MT rainfall with the variability of Z200 in the Northern Hemisphere at a weekly timescale with Z200 leading the MT rainfall by 1 week $(\operatorname{lag}=-1)$. The arch-shaped structure which is visible in Fig. 2c over Europe and central Asia suggests that there could be a wave pattern propagating eastward from western Europe and affecting the MT rainfall with a 1-week lag. This hypothesis will be further tested in the next section. Following DW2005, we define a circumglobal teleconnection index (CGTI) as the weekly mean Z200 spatially averaged over the region $35-40^{\circ} \mathrm{N}, 60-$ $70^{\circ} \mathrm{E}$ (white box in Fig. 2d). The contemporaneous ( $\mathrm{lag}=0$ ) spatial correlation structure between the CGTI and Z200, i.e. the circumglobal teleconnection pattern, is shown in Fig. 2d. A large region of strong positive correlation surrounds the Caspian Sea, while downstream, a circumglobal wave train is shown with four positive centres of action positioned over East Asia, the North Pacific, North America and western Europe. Despite different temporal averaging, using different datasets and the fact that we remove the interannual variability, our results with five centres of positive correlation strongly resemble the circumglobal teleconnection pattern described by DW2005 in terms of sign and the geographical position of its centres of action. Thus, we conclude that the circumglobal teleconnection pattern defined by the CGTI region also manifests at a weekly timescale. Moreover, the wave pattern shown over Eurasia in Fig. $2 c$ and d also resembles the wave pattern identified by DW2007. Thus, this resemblance represents the first hint that the circumglobal teleconnection pattern and the Eurasian wave train analysed by DW2007 share common elements and link the North Atlantic variability to the ISM region. In both Fig. $2 c$ and $2 d$ correlation values with corrected $p$ values $p<0.05$ are highlighted with black contours.

The circumglobal teleconnection pattern (Fig. 2d) shows a very low though significant negative spatial correlation with the EOF1 pattern $(r=-0.09 \pm 0.02$; here and later, $r$ is shown together with its confidence interval at $\alpha=0.05$ ). The spatial correlation of EOF2 (Fig. 2b) with the circumglobal teleconnection pattern (Fig. 2d) over the Northern Hemisphere is $r=0.35 \pm 0.02$, and the spatial correlation with the circumglobal teleconnection pattern increases when limited to the Eurasian sector only $\left(0-90^{\circ} \mathrm{N}-0-150^{\circ} \mathrm{E}, r=\right.$ $0.52 \pm 0.02)$. Contrarily, the spatial correlation with EOF1 and the circumglobal teleconnection is also low when only the Eurasian sector is taken into account $(r=-0.16 \pm 0.03)$. When EOFs are calculated only on the Eurasian sector, the order of the first and second EOFs is reversed, but the spatial patterns are very similar: EOF1 $1_{\text {Eurasia }}$ is strongly spatially correlated with EOF2 $(r=0.89 \pm 0.01)$ and with the circumglobal teleconnection pattern $(r=0.44 \pm 0.02$; see the Supplement, Fig. S3). Thus, the choice of the region to calculate the EOFs does not strongly affect the results. Moreover, since we are interested in the two-way effects of the entire mid-latitude circulation and the MT rainfall, we decided to use the EOFs defined over the entire Northern Hemisphere (as shown in Fig. 2a, b).

The time series for the principal component of EOF2 also significantly correlates with the CGTI time series $(r=0.30 \pm$ 0.07), while the correlation for the first principal component is low and not significant $(r=-0.06 \pm 0.08)$. The circumglobal teleconnection pattern (Fig. 2d) also strongly resembles the correlation structure between MT rainfall and Z200 at lag -1 (Fig. 2c) with a spatial correlation of $0.69 \pm 0.01$. These findings are consistent with those of DW2005 and thus illustrate a likely interaction between MT rainfall and Z200 variability.

Composite $2 \mathrm{~m}$ temperature and precipitation differences for weeks with strong CGTI $\left(\mathrm{CGTI}>1 \mathrm{CGTI}_{\mathrm{SD}}\right.$, where

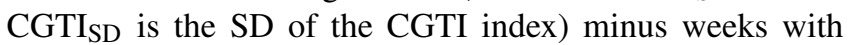
weak CGTI anomalies (CGTI $<-1 \mathrm{CGTI}_{\mathrm{SD}}$ ) also exhibit a clear wave train pattern originating from western Europe and central Europe, respectively. Figure 2e and $\mathrm{f}$ present the corresponding $2 \mathrm{~m}$ temperature and precipitation anomalies from the ERA-Interim and CPC-NCEP dataset, respectively, showing anomalies with $p$ values $p<0.05$ as shaded and highlighting anomalies that have corrected $p$ values $p<0.05$ by black contours. In both variables, a wave train from western-central Europe to India via European Russia is detected (in Fig. 2e and f, highlighted by a black arrow). Wet and cold anomalies appear over central India and European Russia, while warm and dry anomalies are found over western-central Europe and east of the Caspian Sea. Warm anomalies appear together with the high and low features shown in the circumglobal circulation pattern over Europe and central Asia (Fig. 2d); however, precipitation anomalies show a slight eastward shift with respect to temperature anomalies. Precipitation anomalies are more spatially confined than those found for $2 \mathrm{~m}$ temperature. However, a clearly defined wave pattern appears over the Eurasian sector for both variables. Though these plots are obtained by plotting composites of weeks with CGTI $>1 \mathrm{CGTI}_{\mathrm{SD}}$ minus composites of weeks with CGTI $<-1 \mathrm{CGTI}_{\mathrm{SD}}$, we have found that these composites behave close to linearly when plotted separately (see the Supplement, Fig. S4). This further supports the assumption that a linear framework is a reasonable choice in this context. Moreover, when regressing the MT rainfall on the CGTI index at different lags (from lag 0 to lag -2 weeks), the strongest relationship between the CGTI and the CPC-NCEP rainfall is found at lag $=-1$ week, with the CGTI leading a change in MT rainfall by 1 week (see the Supplement, Fig. S5). This information also further supports 
(a)

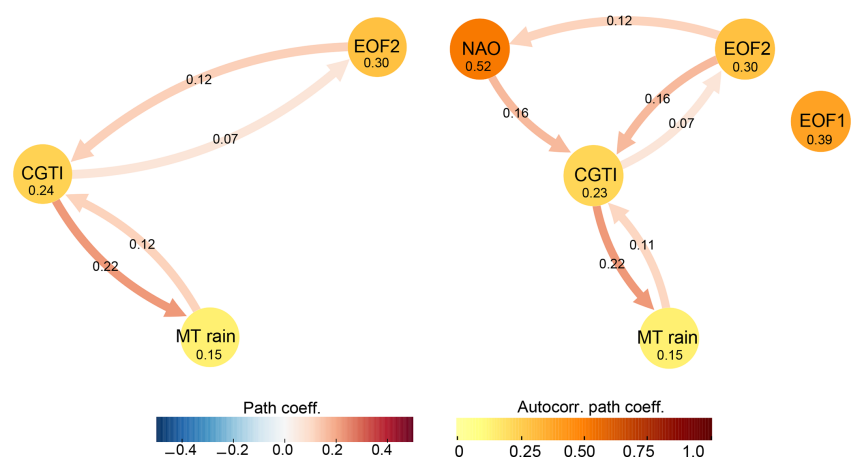

Figure 3. Causal mid-latitude interactions with the ISM. (a) Causal effect network (CEN) built with CGTI, the principal component of EOF2 and MT rainfall for the period 1979-2017. (b) Same as panel (a) but with the addition of the principal component of EOF1 and NAO. The strength of the causal links expressed by the standardized regression path coefficients and autocorrelation path coefficients is shown over the arrows and inside the circles, respectively. All links have a lag of 1 week. Only causal links with corrected $p<0.05$ are shown. See the main text for discussion.

the choice of analysing the relationships between these two variables at lag $=-1$ week.

Based on the DW2005 hypothesis, we build a CEN with CGTI, MT rainfall and the principal component of EOF2 (Fig. 3a). This CEN depicts a positive two-way connection both between CGTI and MT rainfall and between CGTI and EOF2. This implies that anomalously high CGTI values (with relatively high Z200 east of the Caspian Sea) enhance MT rainfall at a 1-week lag, while lower CGTI values have the opposite effect. Note that the causal effect here is always acting in the direction of the arrow with a lag of 1 week; e.g. the arrow from CGTI towards MT rainfall represents a causal effect of 0.22 (given by the colour) from CGTI to MT rainfall with a lag of 1 week. The link directed from MT rainfall to CGTI illustrates a reverse influence, creating a positive feedback between CGTI and MT rainfall and supporting the monsoon-circumglobal teleconnection pattern hypothesis. The strength of the causal link between the CGTI and MT rainfall is expressed by the path coefficients (see the "Data and methods" section).

The causal link strength of the CGTI acting on the MT rainfall is $\beta_{\mathrm{CGTI} \rightarrow \mathrm{MT}} \sim 0.2$ (meaning that a change of $1 \mathrm{SD}$ in CGTI leads to a change of 0.2 SD in MT rainfall, while the reverse link is weaker $\left(\beta_{\mathrm{MT} \rightarrow \mathrm{CGTI}} \sim 0.1\right)$ but still significant. EOF2 shows a two-way link with the CGTI. The links between EOF2 and CGTI support the DW2005 hypothesis that wave trains in the mid-latitudes (represented by EOF2) affect the MT rainfall via the CGTI.

To assess whether the North Atlantic variability affects the MT rainfall (as hypothesized by DW2007), we add the NAO index to our original CEN. In order to check whether the first mode of variability in the Northern Hemisphere may also play a role in shaping MT rainfall variability, we additionally include EOF1. Figure $3 b$ shows the resulting CEN: the causal links identified in the previous CEN (Fig. 3a) remain unaltered, and two additional positive links from NAO to CGTI and from the EOF2 to the NAO emerge. A positive NAO phase will strengthen the CGTI at 1-week lag $\left(\beta_{\mathrm{NAO} \rightarrow \mathrm{CGTI}} \sim 0.2\right)$, while the NAO is influenced by EOF2 $\left(\beta_{\mathrm{EOF} 2 \rightarrow \mathrm{NAO}} \sim 0.1\right)$, though weakly. EOF1 does not show a causal connection with CGTI or with any other actor, showing that in this context, EOF1 and EOF2 present a different behaviour, though in principle not statistically separated following the North test. This CEN unveils both an influence of the mid-latitude atmospheric dynamics (EOF2) and North Atlantic variability (NAO) on MT rainfall and back, with the CGTI acting as a gateway, thus supporting both the DW2005 and DW2007 hypotheses. Substituting EOF2 with its corresponding EOF calculated over the Eurasian sector, EOF1 $1_{\text {Eurasia }}$, shows consistent results (see the Supplement, Fig. S6).

\subsection{Eurasian and North Atlantic mid-latitude features affecting the Indian summer monsoon}

The EOF-based CEN analysis depicts the total hemispheric response of Z200 without differentiating among the influences of different geographical regions. To detect influential regions, we next apply the response-guided causal precursor detection (RG-CPD) scheme to search for causal precursors of both the CGTI and MT rainfall at 1-week lead time in weekly OLR and Z200 fields. In the tropical belt, OLR is often used as a proxy for rainfall and convective activity due to its relation with the temperature at the top of the clouds. Deep convection is characterized by high-altitude cloud tops and low emission temperatures (and thus low OLR values), while in clear-sky conditions, the emission temperature of the land surface is higher and leads to larger OLR values (Krishnan et al., 2000).

Figure 4 summarizes our corresponding findings. Figure $4 \mathrm{~d}$ shows the MT region and represents lag 0. Moving towards the left, Fig. $4 \mathrm{c}$ shows the correlation maps (top) and causal precursors (bottom) of the MT rainfall identified at 1-week lead time in Z200. Causal precursors describe an arch-shaped wave train from western Europe to India. The wave train features one low-pressure region (L1 over European Russia) and two high-pressure regions (the CGTI and H1 over western Europe). Figure $4 \mathrm{a}-\mathrm{b}$ show the correlation maps (top) and causal precursors (bottom) of the CGTI identified in the Z200 and OLR fields at 1-week lead time with respect to the CGTI (2-week lead time with respect to the MT rainfall). Again, both the Z200 and OLR correlation maps show an arch-shaped wave pattern emanating from the North Atlantic and propagating towards the Caspian Sea via European Russia. The associated Z200 causal precursors for the CGTI clearly depict this mid-latitude wave train both in Z200 and OLR (Fig. 4a, b). In the Z200 field (Fig. 4a), 


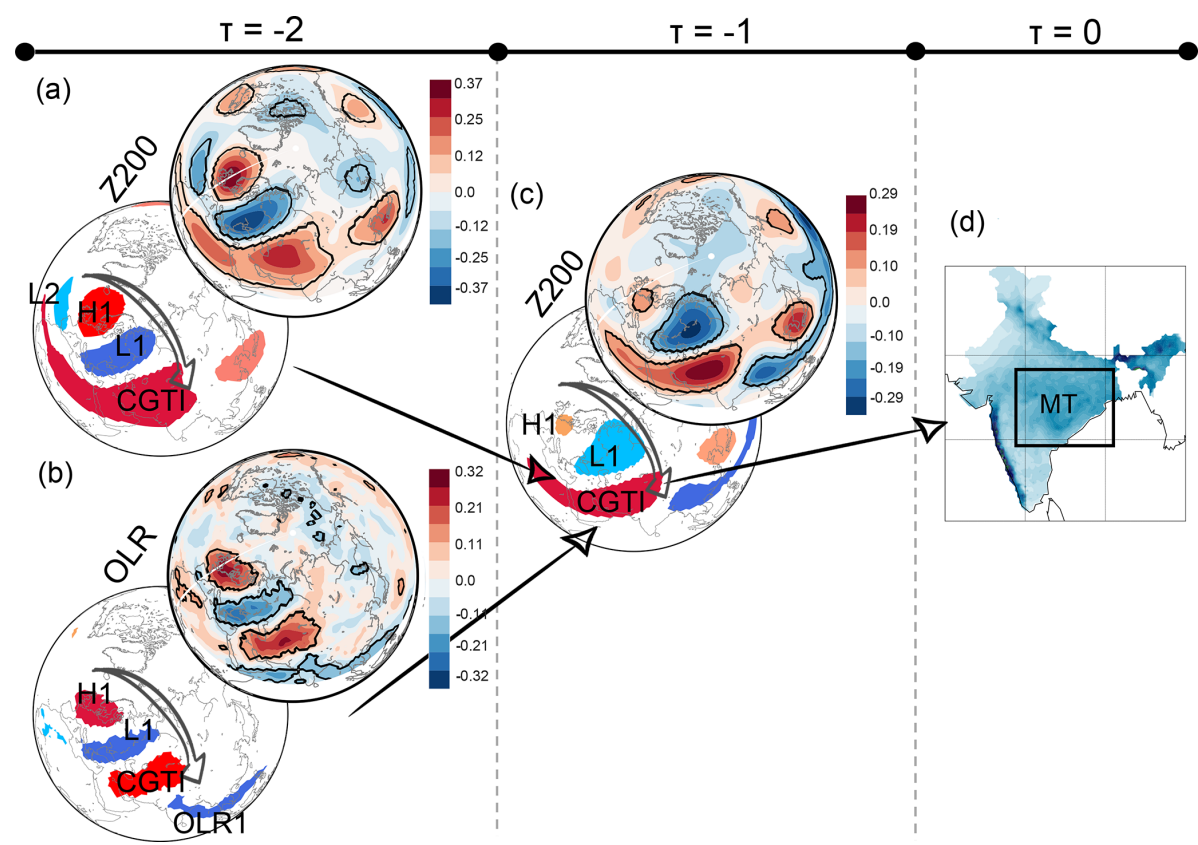

Figure 4. Mid-latitude causal precursors of ISM. (a) Correlation of CGTI with Z200 at 1-week lead time (top) and the causal precursors of CGTI identified via RG-CPD (bottom) for the period 1979-2017. (b) As for panel (a) but for OLR fields. (c) Correlation map for weekly MT rainfall and Z200 field at 1-week lead time (top) and the causal precursors identified via RG-CPD (bottom). (d) ISM rainfall over the MT region from the Pai et al. (2015) dataset (reproduced from Fig. 1a). Regions with correlation values with a $p$ value of $p<0.05$ (accounting for the effect of serial correlations) are shown by black contours.

the wave train features two lows (L1 over European Russia and L2 over the eastern North Atlantic) and two highs (the CGTI and H1 over western Europe). OLR causal precursors (Fig. 4b) depict only the L1 and H1 components of the wave, as the correlation over L2 is not significant. Moreover, the prominent influence of the tropical belt on the CGTI is also detected (OLR1; Fig. 4b), in agreement with previous findings (see Fig. 3). This result further supports the hypothesis that a wave train coming from the mid-latitudes influences the ISM circulation system via the CGTI region as already shown in Fig. 2, while strong temperature and precipitation anomalies shown in Fig. 2e and $\mathrm{f}$ coincide markedly with the regions H1, L1 and CGTI identified in Fig. 4a and c. Figure 4a shows a North Atlantic pattern that resembles a negative NAO, whereas Fig. $3 \mathrm{~b}$ indicates a positive causal link from NAO on CGTI. This seeming mismatch is explained by the difference in pressure level and lead time with a more positive NAO pattern at lag -2 (see the Supplement, Fig. S7).

The CEN built with MT rainfall, CGTI and the upstream part of the mid-latitude wave train, i.e. L1 and H1, is shown in Fig. 5. The causal links between the CGTI and the MT rainfall remain unaltered (see Fig. 3), with the CGTI mediating the connection between the mid-latitude wave (represented by $\mathrm{H} 1$ and L1) and the MT rainfall. Further, the obtained CEN can be interpreted as a wave train that propagates eastward from the eastern Atlantic towards the Indian mon- soon region, as postulated by DW2007. Let us focus on the connections between $\mathrm{H} 1$ and L1. If $\mathrm{H} 1$ increases, then L1 decreases at 1-week lag. The backward link is positive: thus, if L1 increases H1 also increases at 1-week lag. This dampening loop is easiest explained by an eastward-propagating wave. To illustrate this, we design a simple experiment using synthetic time series representing a simple cosine wave propagating eastward with added noise sampled at two locations. We estimate the wavelength, wave speed and amplitude based on the observed properties of H1 and L1 (see the Supplement, Figs. S8-S9). The CEN resulting from these time series is equivalent to that of $\mathrm{H} 1$ and $\mathrm{L} 1$ in Fig. 5, with a negative forward link and a positive backward link. Physically, this can be understood by a travelling wave amplifying in the forward direction but at the same time dampening in the backward direction.

\subsection{Intraseasonal variability and tropical influence on the monsoon circulation}

Next, we perform a similar analysis applying RG-CPD to fields of vertical wind velocities (W500) and OLR to capture the internal feedbacks and dynamics of the ISM convective updraft. Their correlation maps and detected causal precursors are shown in Fig. 6a and b. MT rainfall has four causal precursors in OLR. A large region extending from the Arabian Sea towards the Maritime Continent via the Indian 


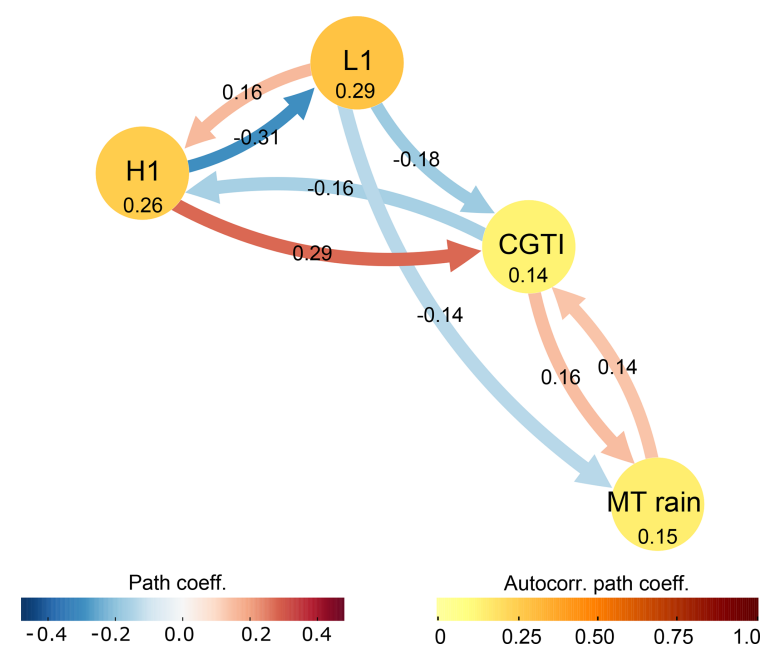

Figure 5. Mid-latitude wave train. CEN built with the MT rainfall, CGTI, L1 and H1 (as identified in Fig. 4a) for the period 1979-2017. The strength of causal links expressed by the standardized regression path coefficients and autocorrelation path coefficients is shown above the arrows and inside the circles, respectively. All links have a lag of 1 week. Only causal links with corrected $p<0.05$ are shown. See the main text for discussion.

subcontinent (OLR1; Fig. 6a) shows a negative causal link, while another region covering parts of the Tibetan Plateau shows a positive causal link (OLR2; Fig. 6a). A third region is found north-east of the Caspian Sea, over western Russia (OLR3) with a negative causal relationship with MT rainfall. A fourth, though small, region of positive correlation is found over the equatorial Indian Ocean (OLR4; Fig. 6a). OLR1 spatially overlaps $\mathrm{W} 1$, the largest causal precursor in the vertical wind field, representing the north-west-south-east-tilted rainfall band related to the BSISO over the northern Indian Ocean and western Pacific Ocean (Fig. 6b, top panel). The positive correlation of $\mathrm{W} 1$ and negative correlation of OLR1 with MT rainfall indicate that ascending motions and associated high-level cloud formation are followed by enhanced rainfall over the MT region with a lag of 1 week. OLR2 and OLR3 largely overlap the regions L1 and the CGTI region identified in Fig. 4c, further supporting the importance of this mid-latitude wave pattern in modulating the rainfall over the MT region also when a different variable is selected. OLR4 hints to the presence of a see-saw of enhanced and suppressed convective activity alternating between the equatorial Indian Ocean and the Indian Peninsula, likely related to the northward propagation of the BSISO.

Figure $6 \mathrm{c}$ and $\mathrm{d}$ show two CENs constructed from the MT rainfall causal precursors in OLR and W500 (region OLR1 as defined in Fig. 6a and W1 as defined in Fig. 6b), including CGTI and MT rainfall itself. Since the OLR and W500 fields present less organized large-scale spatial patterns than Z200, we use only the two dominant causal precursors. Although the regions OLR1 and W1 show a large spatial over- lap, they represent two different components of the ISM system. OLR is calculated at the top of the atmosphere, with low OLR values representing strong convective motions. W500 is calculated at $500 \mathrm{hPa}$, and $\mathrm{W} 1$ thus represents the ascending branch of the ISM circulation cell and nearby BSISO. The CEN built with OLR1, W1 and the MT rainfall at a weekly timescale (Fig. 6c) represents the intraseasonal variability of the monsoon circulation and therefore its relation with the BSISO and the initiation of active and break phases. Enhanced vertical motions (W1) precede an increase in the MT rainfall by 1 week; seemingly, more clouds (lower OLR1) are associated with enhanced W1 1 week later (thus enhancing the ISM circulation). Contrarily, enhanced rainfall shows a negative feedback on both OLR1 and W1: stronger MT rainfall leads to reduced vertical motions and clearer skies (lower W1 and higher OLR1, respectively). Hence, this CEN depicts a negative feedback intrinsic to the ISM intraseasonal variability: while enhanced ascending motions and thus strengthened ISM circulation lead to stronger MT rainfall, enhanced rainfall leads to weaker ISM circulation and in turn diminished MT rainfall, hinting to an alternation of rainy and dry periods over the MT region, likely related to the alternation of active and break phases. Thus, from a physical point of view, this can be explained in two ways: (1) as a see-saw representing the switch of the ISM system between an active and a break phase and (2) via an increase in atmospheric static stability due to latent heat release in the higher layers of the troposphere. The latter mechanism is further analysed in Fig. S10 (see the Supplement), where we build a CEN with MT rainfall, sea level pressure (SLP) over the Bay of Bengal (SLP_BOB), temperature at $400 \mathrm{hPa}$ (Tp4_MT) and temperature at $600 \mathrm{hPa}$ (Tp6_MT). The resulting causal links show that while a decrease in SLP over the Bay of Bengal is followed by an increase in MT rainfall and both Tp4_MT and Tp6_MT, an increase in Tp4_MT (thus enhanced static stability) leads to a decrease in MT rainfall. The described mechanism is in agreement with what was proposed by Saha et al. (2012) and Krishnamurti and Bhalme (1976).

Next, we test the causal relationships identified between MT rainfall and W1 when adding the CGTI and MJO variability to the CEN (Fig. 6d). MJO variability is expressed by the OMI PC2 (here referred to as MJO2), the second EOF of OLR in the tropical belt (Kiladis et al., 2014). OMI PC2 corresponds to the RMM1 index, widely used in previous work on the relationship between the MJO and the ISM (Pai et al., 2011; Kiladis et al., 2014; Mishra et al., 2017). Positive RMM1 values correspond to MJO phases 3-6 (also referred to as the active phases of $\mathrm{MJO}$ ) and physically represent the presence of strong convection activity propagating eastward from the Indian Ocean towards the western Pacific. Several studies show that MT rainfall is enhanced during active MJO phases (Pai et al., 2011; Mishra et al., 2017; Anandh et al., 2018). Moreover, in summer the OMI also represents the BSISO, further linking OLR1 and W1 to BSISO-related convective activity (Wang et al., 2018). In this 
(a)

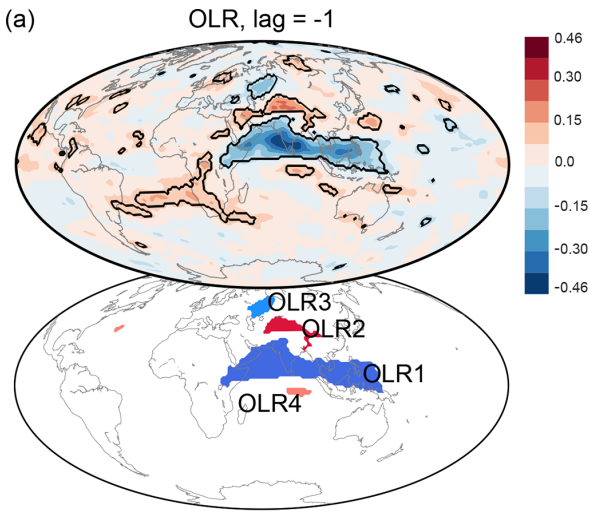

(c)

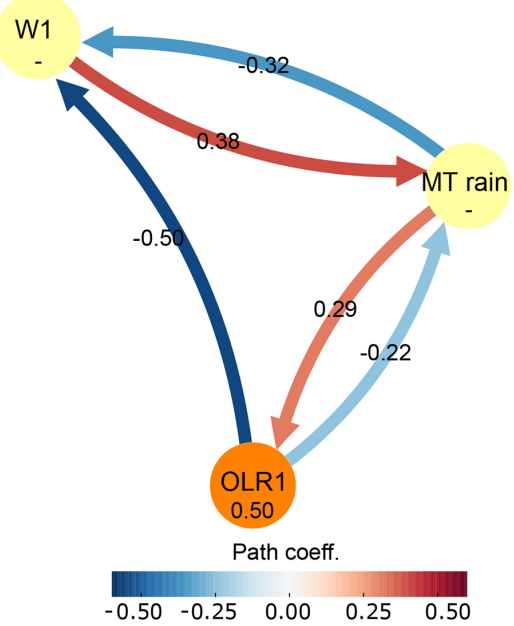

(b)

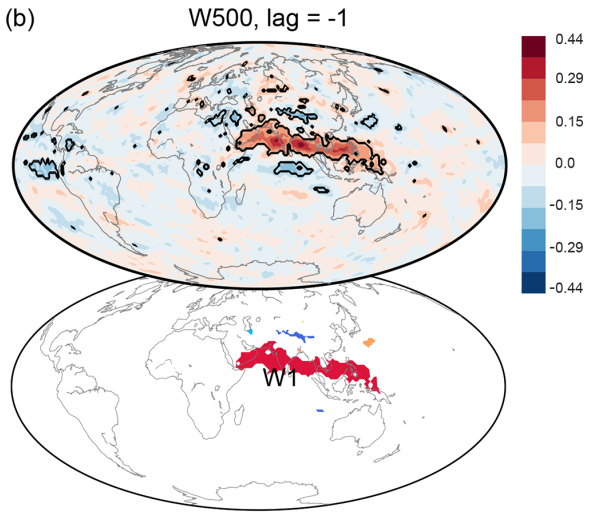

(d)

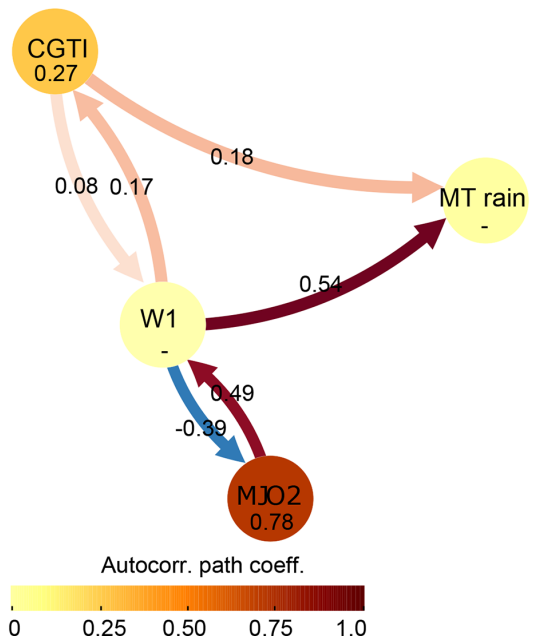

Figure 6. Tropical causal interactions of ISM. Panel (a) shows the correlation map of weekly MT rainfall with the global OLR field at 1-week lead time (top) and the causal precursors identified via RG-CPD (bottom) for the period 1979-2017. Regions with correlation values with a $p$ value of $p<0.05$ (accounting for the effect of serial correlations) are shown by black contours. (b) As for panel (a) but for the W500 field. Panels (c) and (d) show the CEN built with W1, OLR1 and MT rainfall and MT rainfall, W1, CGTI and MJO2, respectively. The strengths of causal links expressed by the standardized regression path coefficients and autocorrelation path coefficients are shown above the arrows and inside the circles, respectively. All links have a lag of 1 week. Only causal links with corrected $p<0.05$ are shown. See the main text for discussion.

CEN, the link from the MT rainfall towards W1 remains unaltered (while the link in the opposite direction disappears, indicating that this link is less robust than the others), while the CGTI shows a positive feedback with W1: an increase in the CGTI causes stronger ascending motions (W1), while stronger ascending motion over the Indian region strengthens the CGTI. The CGTI has a direct positive causal link to MT rainfall (Fig. 6d). Even though the direct link from MT rainfall to CGTI has now disappeared (likely because this link was already relatively weak in a simpler CEN configuration; see Fig. 3a), the link between the ISM circulation and the mid-latitudes remains via W1. Stronger updraft over the ISM and the Maritime Continent regions (higher W1) leads to increased CGTI and vice versa as seen in Fig. 3, where higher CGTI leads to enhanced MT rainfall, both directly and via $\mathrm{W} 1$. MJO2 displays a positive causal link with $\mathrm{W} 1$, meaning that OMI PC2 positive values lead to enhanced vertical motions with 1-week lead time and, as a consequence, enhanced MT rainfall with 2-week lead time. However, stronger W1 leads to decreased MJO2 (negative causal link from W1 to MJO2). Thus, MJO2 shows exactly the same causal relationships (but opposite signs) with W1 as shown for OLR1 in Fig. 6c, likely because the OMI is also defined based upon OLR fields in the tropical belt and the OLR pattern shown by the second EOF of the OMI largely overlaps our OLR1 region (Kiladis et al., 2014).

We checked how these links decay over time and found that the causal links from W1 to the CGTI and from the CGTI to the MT rainfall remain stable at lag -2 weeks but then decay to zero at lag -3 weeks. The causal effect from W1 on the MT rainfall and from $\mathrm{MJO} 2$ to $\mathrm{W} 1$ drops to values close to zero at lag -2 and -3 (see the Supplement, Fig. S11). 
This result is further visible if the timescale is changed from weekly to monthly: in this case, the spatial correlation between the circumglobal teleconnection pattern and the correlation map between MT rainfall and Z200 at lag 0 is still high $(r=0.79)$. However, when the correlation is calculated between MT rainfall and Z200 at lag -1 (month), the map becomes non-significant (see the Supplement, Fig. S12). This result further suggests that these causal relationships have a characteristic timescale shorter than 1 month and of about 1-2 weeks. Moreover, OLR shows no significant correlation patterns with the MT rainfall, and no significant causal links are detected between MT rainfall and the CGTI at a monthly timescale (not shown).

\subsection{Combining local, tropical and mid-latitude causal interactions}

Finally, we bring together the findings obtained with CEN and RG-CPD throughout this study and summarize them in a single CEN to provide an overall picture and test the consistency of the results. We include the most important identified regions from both the tropics and the mid-latitudes together in a single CEN (Fig. 7) and plot the corresponding CEN over a map to help the reader associate each actor with its corresponding approximate region (though in cases when the index is defined over all longitudes, such as EOF2, it is only possible to associate the actor with its average latitude). Specifically, this CEN is built with elements that come from both the DW2005 and DW2007 hypotheses (Fig. 3) and from our RG-CPD analysis (Figs. 4 and 6). Moreover, to test the consistency of the results under a change in rainfall dataset, we also performed the same analysis using the CPC-NCEP rainfall dataset over the period 1979-2016 (see the Supplement, Figs. S13-S19) and found that our results are robust when using the CPC-NCEP rainfall dataset. In Fig. 7, all causal links are reproduced with the same directions, and only the magnitudes of the causal effects exhibit minor changes with respect to the CEN shown in Figs. 3 and 6. Our results show that the influence of both the mid-latitude circulation (EOF2) and the North Atlantic (NAO) on the MT rainfall is mediated via the CGTI and is robust: the structure and the direction of the causal links are retained. The backward influence of the MT rainfall on the mid-latitude circulation is weaker and more complex, as already shown in Fig. 6d. CGTI has both a direct causal link to MT rainfall and an indirect one via $\mathrm{W} 1$.

MT rainfall and W1 show a negative feedback (though the link from the MT rainfall towards W1 is only significant when CPC-NCEP rainfall data are used; see the Supplement, Fig. S19), with increased W1 leading to enhanced MT rainfall but stronger MT rainfall leading to weaker W1. The MT rainfall is also influenced by MJO2 via W1 with a two-way connection. Higher MJO2 values (linked to the MJO phases 3 to 6) are followed by stronger upward motions (increased W1) 1 week later, which in turn causes enhanced MT rain-

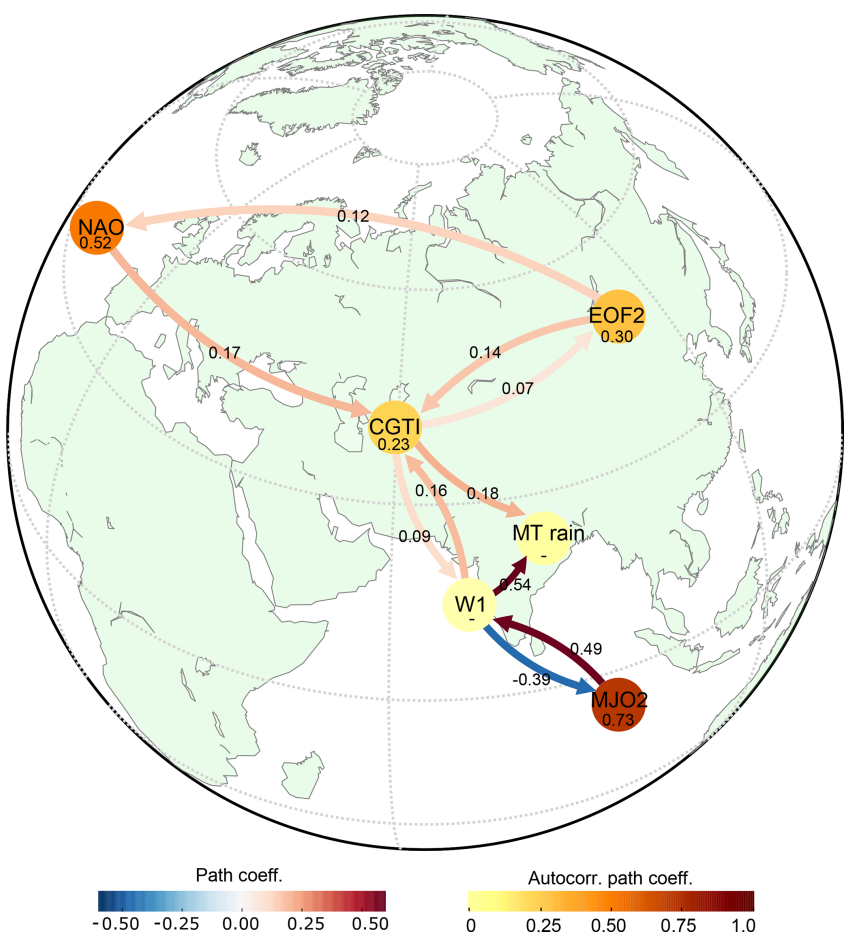

Figure 7. Combined mid-latitude and tropical causal interactions of ISM. CEN built with W1, MJO2, MT rainfall, NAO, CGTI and EOF2 for the period 1979-2017. The strengths of causal links expressed by the standardized regression path coefficients and autocorrelation path coefficients are shown above the arrows and inside the circles, respectively. All links have a lag of 1 week. Only causal links with corrected $p<0.05$ are shown. See the main text for discussion.

fall 2 weeks later (with respect to MJO2). In the opposite direction, suppressed or weakened ascending motions promote lower MJO2 1 week after, thus promoting the switch toward MJO phases 7-8 and 1-2, also known as suppressed MJO phases. Suppressed MJO phases are in turn linked with the onset of break phases of the Indian monsoon (Pai et al., 2011).

To quantify the relative influence of tropical and midlatitude teleconnections on MT rainfall, we report the causal effect (CE) strength of each link, which is given by the path coefficient in the CEN (see Fig. 7 and Table S1 in the Supplement). W1 has the strongest causal effect on MT rainfall with $\beta_{\mathrm{W} 1 \rightarrow \mathrm{MT}}=0.54$, implying that a $1 \mathrm{SD}$ shift in $\mathrm{W} 1$ causes about a $0.5 \mathrm{SD}$ change in MT rainfall after 1 week (under the previously mentioned conditions; see the "Data and methods" section). The CGTI influences MT rainfall directly and indirectly via $\mathrm{W} 1$, and the total causal effect is given by $\beta_{\mathrm{CGTI} \rightarrow \mathrm{MT}}+\beta_{\mathrm{CGTI} \rightarrow \mathrm{W} 1} \times \beta_{\mathrm{W} 1 \rightarrow \mathrm{MT}}=0.23$, where $\beta_{\mathrm{CGTI} \rightarrow \mathrm{MT}}=0.18$ and $\beta_{\mathrm{CGTI} \rightarrow \mathrm{W} 1}=0.09$. The causal effect of CGTI is thus roughly half as strong as that of the intraseasonal variability of the Indian monsoon system as represented here by $\mathrm{W} 1$. MJO2 has a causal effect on 
$\mathrm{W} 1$ of $\beta_{\mathrm{MJO} 2 \rightarrow \mathrm{W} 1}=0.49$ and is influenced by $\mathrm{W} 1$ with $\beta_{\mathrm{W} 1 \rightarrow \mathrm{MJO} 2}=-0.39$. Looking more specifically at the causal effect of MJO2 on MT rainfall mediated via $\mathrm{W} 1$, we find $\beta_{\mathrm{MJO} 2 \rightarrow \mathrm{W} 1} \times \beta_{\mathrm{W} 1 \rightarrow \mathrm{MT}}=0.26$; i.e. the tropical driver effect on MT rainfall itself is similar in magnitude to that of CGTI as for the key extratropical driver. Thus, taking both $\mathrm{W} 1$ and MT as representatives of ISM intraseasonal variability, the effects of external drivers from both the tropics and midlatitudes on the ISM circulation are both about half as strong as that of W1 on MT. For comparison, the path coefficients for all the identified causal links are reported together with the corresponding Pearson correlations of each pair of variables (see the Supplement, Table S1). In general the values of the causal effect and the simple correlation do not differ greatly, despite a few exceptions for which linear correlation is not significant even though there is a causal link or when the sign of the causal effect and the simple correlation differ. However, one should not forget that plain correlation does not indicate causality, nor can it identify chains of causality between different variables.

Moreover, we calculate the average causal effect (ACE) and average causal susceptibility (ACS) for each actor. While ACE gives a measure of the causal effect that each actor has on the rest of the network, ACS measures the sensitivity of each actor to perturbations entering any other part of the network (Runge et al., 2015). In this CEN, W1 has the highest ACE $(\sim 0.22)$ and both CGTI and MJO2 the second highest ACE $(\sim 0.10)$. MT rainfall and W1 show the strongest ACS $(\sim 0.1)$. ACE and ACS values for each actor are further summarized in Table S2; see the Supplement. These values again stress the importance of both ISM intraseasonal variability and CGTI in mediating mid-latitude waves towards the ISM.

Finally, we test for the robustness of the causal links when different regions other than the MT area are studied. In general, analysing Indian summer monsoon rainfall (ISMR), rainfall in the western Himalayan foothills (WHF; defined over $26-35^{\circ} \mathrm{N}$ and $70-83^{\circ} \mathrm{E}$ ) or the eastern Himalayan foothills (EHF; defined over $20-30^{\circ} \mathrm{N}$ and $87-$ $97^{\circ} \mathrm{E}$ ) does not affect the strength or the sign of the causal links (see the Supplement, Figs. S20-S21), thus showing that our results are robust and can actually represent the dynamics of the entire ISM basin. This is likely a consequence of the fact that ISMR strongly reflects the behaviour of the MT rainfall $(r=0.57 \pm 0.05)$, as the most abundant rainfall takes place here. While the correlation between ISMR and WHF rainfall is lower ( $r=0.35 \pm 0.06$ ), the same causal links as for the MT rainfall are observed, suggesting a strong similarity in the dynamical mechanisms that govern MT and WHF rainfall. However, when EHF rainfall is taken into account, the correlation with the ISMR is low and not significant $(r=0.03 \pm 0.05)$. As a consequence, the links from the CGTI and W1 to EHF disappear (though all other links are left unchanged). This suggests that the dynamical mechanisms that bring abundant rainfall to this region are different from those that determine the MT rainfall (see the Supplement, Fig. S21).

\section{Discussion and conclusions}

In this study, we apply causal discovery algorithms to analyse the influence of global middle and upper tropospheric fields on weekly ISM rainfall and study the twoway causal links between the mid-latitude circulation and ISM rainfall, together with tropical drivers and ISM intraseasonal variability. We perform a validation of both the monsoon-circumglobal teleconnection hypothesis proposed by DW2005 and the North Atlantic-monsoon connection proposed by DW2007 using causal discovery tools. We use the response-guided causal precursor detection (RG-CPD) scheme to detect causal precursors from both mid-latitude and tropical regions and then apply causal effect networks (CENs) to assess the influence of different drivers of MT rainfall and their relative contribution to the MT rainfall intraseasonal variability.

The new findings of this work can be summarized in two main aspects: first, we prove the DW2005 hypothesis from a causal point of view, showing that the hypothesized twoway link between the MT rainfall and the mid-latitude circulation can be demonstrated in a causal framework. Second, we quantify the relative importance of (a) the mid-latitude circulation, (b) the intraseasonal variability and (c) the tropical drivers of the ISM circulation, showing a link that connects the boreal summer intraseasonal oscillation (BSISO) and the Madden-Julian oscillation (MJO) to the ISM intraseasonal variability (see Fig. 7 and Table S1 in the Supplement). Moreover, we also show that the circumglobal teleconnection hypothesis by DW2005, initially defined at a seasonal and/or monthly timescale, also holds at an intraseasonal (weekly) timescale and can be unified with the hypothesis by DW2007, which analysed wave trains propagating from the North Atlantic toward the MT region at a 2-week timescale. Thus, we argue that the CGTI region and the midlatitude circulation are important for both the intraseasonal and seasonal variability of the MT rainfall. An explanation for this could be that the seasonal and/or monthly representation of the monsoon-circumglobal teleconnection interaction is actually strongly influenced by mechanisms that act on intraseasonal timescales, similarly to what has been proposed by Stephan et al. (2019), who come to a similar conclusion but analysing the causal interaction between the Silk Road pattern and the monsoon-desert mechanism. Here, a hint in this direction is provided by the analysis of the monsooncircumglobal teleconnection link at a monthly timescale: while the spatial correlation between the MT rainfall and the Z200 field at lag 0 strongly resembles the circumglobal teleconnection pattern (when monthly averages are analysed), this similarity disappears when Z200 leads the MT rainfall by 1 month (see the Supplement, Fig. S12). Therefore, we 
suggest that the mechanism responsible for the monsooncircumglobal teleconnection is acting at a timescale shorter than 1 month.

Our causal analyses confirm the influence of the midlatitude circulation on MT rainfall via the CGTI, as hypothesized by DW2005. We also confirm that MT rainfall forces the mid-latitude circulation via the CGTI, but this link is weaker (see the Supplement, Fig. S18). We test the sensitivity of the monsoon-circumglobal teleconnection hypothesis to changes in the selected rainfall region, showing the general robustness of the identified causal links. Both Indian summer monsoon rainfall (ISMR) and WHF rainfall behave consistently with the MT rainfall (see the Supplement, Figs. S20S21). These similarities are likely due to the strong correlation that exists between the MT rainfall and ISMR, with the MT rainfall being one of the dominant features of the ISM intraseasonal variability (Krishnan et al., 2000). However, EHF rainfall is found to behave differently, and does not show any connection with the updraft region identified by W1. This is likely related to the fact that the EHF region receives heavy rainfall amounts during the early stage of a break event, and thus it is likely to be affected by different circulation patterns than those that govern the MT rainfall (Vellore et al., 2014). Nevertheless, also in this case, all other causal links in the CEN are retained.

Next to the influence of the MT rainfall, our analysis also shows that the link between the circumglobal teleconnection pattern and the ISM can be seen in the wider perspective of the BSISO variations. Our OLR1 and W1 regions (see Fig. 6a, b) show a north-west-south-east-tilted rainfall band with great similarities to the BSISO rainfall band (Wang et al., 2018). In light of this relationship, the negative feedback that characterizes the causal links between $\mathrm{W} 1$ and the MJO2 (see Fig. 6d) and between the MT rainfall and W1 (see Fig. S18 in the Supplement) can be interpreted as the shift of the ISM system between a break and an active phase and to the north-eastward propagation of BSISO convective anomalies. Therefore, while on the one hand we analyse MT rainfall (which is directly linked to active and break phases at intraseasonal timescales), on the other hand our W1 region also represents the BSISO influence on the monsooncircumglobal teleconnection mechanism, thus linking the mid-latitude circulation not only to local latent heat release connected to the MT rainfall, but also to the wider updraft region related to the South Asian monsoon in its broader definition that closely resembles the BSISO rainfall band. This connection is supported by the fact that the direct link from the MT rainfall to the CGTI disappears when $\mathrm{W} 1$ is added to the CEN (see Fig. 6). While an indirect link from the MT rainfall to the CGTI remains via $\mathrm{W} 1$, the disappearance of the direct link indicates that the influence of W1 on the CGTI is stronger than the direct link from the MT rainfall.

Applying RG-CPD, we find a wave train that emanates from the eastern North Atlantic stretching towards India via Europe and western Russia. This wave pattern is visible in geopotential height fields as well as temperature and precipitation anomalies and acts on MT rainfall via the CGTI with a 1-2-week lead time, in agreement with the DW2007 hypothesis and with previous studies showing that there is a connection from the North Atlantic toward the ISM system (Goswami et al., 2006). Moreover, the larger CGTI region as defined in Fig. 4c, while showing the strongest correlation over the CGTI region as defined in Fig. 2d, also stretches south-westwards towards north-east Africa to the area that features the downdraft related to the monsoon-desert mechanism (Rodwell and Hoskins, 1996). Therefore, our work is in agreement with previous findings that show an influence of the ISM latent heat release on north-east African arid conditions via the excitation of Rossby waves to the west. However, here we focus on the relationship between the MT rainfall and the circumglobal teleconnection pattern; thus, a link from the MT rainfall towards the Saharan region cannot be inferred from this analysis. Moreover, the causal relationship between the north-eastern Indian rainfall and the downdraft over the north-eastern Sahara related to the monsoon-desert mechanism has already been shown (Stephan et al., 2019).

Our results show that RG-CPD can detect well-known circulation features of the MT rainfall with 1-week lead time without using any a priori theoretical or geographical constraint to select the causal precursors among all precursor regions, demonstrating the efficacy of the presented method. Moreover, causal discovery tools can quantify the causal influence of tropical drivers versus mid-latitude influences and BSISO on the ISM intraseasonal circulation dynamics.

The intraseasonal variability of the ISM system, here represented by the updraft region identified by $\mathrm{W} 1$, has the strongest effect on MT rainfall. The influence from the midlatitudes on MT rainfall, as mediated by CGTI, is about half of the magnitude of that of the internal dynamics, while the influence of MJO as the key tropical driver of MT rainfall is only slightly weaker (Fig. 7). However, when taking MT rainfall and the vertical wind field over the Indian subcontinent together as two interdependent yet different facets of the ISM, we find that the general effect of tropical drivers (MJO) on the system is slightly stronger than that of the extratropical drivers, while looking on the one hand at the effect of MJO on the circulation and on the other hand at the total effect of CGTI on MT rainfall via both directed linkages and through a parallel influence on the vertical wind field over India. Though in this framework a direct influence of higher latitudes on the MT rainfall it is not identified, this may depend on the choice of the analysed (intraseasonal) timescale. However, an influence from the Arctic on the ISM rainfall has been identified at longer (inter-seasonal) timescales and has been shown to provide some forecast skill for seasonal Indian summer monsoon rainfall (ISMR) at 4- and 2-month lead times (Rajeevan et al., 2007; Di Capua et al., 2019).

The reported findings are in good agreement with the existing literature. It is well known that intraseasonal variability dominates ISM interannual variability (Goswami and Xavier, 
2005; Suhas et al., 2012). Our causal approach enables us to quantify the relative importance of local internal dynamics, separate it from the influence of remote actors and remove spurious factors. The negative feedback in the ISM intraseasonal variability, here represented by the opposite relationship between MT rainfall and W1 (see Figs. 6d and 7), features a switch from an active to a break phase inside the ISM system, likely linked to the BSISO. Other physical mechanisms can include both radiative effects (Krishnamurti and Bhalme, 1976) and local changes in static stability due to the latent heat release that follows convective precipitation (Saha et al., 2012). While strong upward motions precede strong MT rainfall, enhanced rainfall over the W1 region is known to lead the initiation of breaks by 7-10 d (Krishnan et al., 2000). Moreover, suppressed convection over the Bay of Bengal initiated over the tropical Indian Ocean and associated westward-propagating Rossby waves cause break conditions over the monsoon trough (Krishnan et al., 2000). Our results also support previous findings that suggest a link between the active MJO phases (3-6, corresponding to positive RMM1 values) and enhanced ascending motions over the MT region and adjacent Maritime Continent, which in turn promote enhanced MT rainfall (Figs. 6d and 7) (Pai et al., 2011; Mishra et al., 2017; Anandh et al., 2018).

Our theory-guided causal effect network approach, i.e. creating CENs starting from physical hypotheses, enables us to (1) test those hypotheses in a causal framework, thereby removing the influence from spurious correlations, and (2) quantify the relative strength (i.e. the causal effect) of different local and remote actors. With this approach, one can gain insight into which role each part of a complex system such as the ISM circulation plays in relation to the other components. However, domain knowledge is essential to be guided by known physical processes and associated timescales. By combining RG-CPD and CEN, one can test initial hypotheses and perform further more explorative causal analyses to identify new features. For example, in this study, we first identify our initial actors based on the literature. Then, we increase the pool of actors by searching for causal precursors using RG-CPD. Finally, we reconstruct a CEN that combines those findings and helps to put them into a broader context. This approach can be applied to both observational data (as done here) and climate model data to validate the underlying processes behind intraseasonal variability, which might pave the way for improved forecasts.

The described identification and quantification of causal dependences are based on linear statistical models between the different considered variables quantified in terms of partial correlations. While such linear models can provide useful approximations of real-world climate processes, there could be cases in which they miss other existing linkages that are not described by linear functional relationships. In turn, extending the present analysis to a fully nonlinear treatment is straightforward but would come at the cost of much higher computational demands, which is why we have restricted ourselves in this work to the linear case. Nevertheless, accounting for possible nonlinearities may add further information on the inferred mechanisms and should therefore be undertaken in future research.

In conclusion, our results indicate that, on weekly timescales, the strength of the influence from the midlatitudes on MT rainfall itself is as large as that from the tropics (MJO) but about a factor of 2 smaller than the ISM intraseasonal variability. However, the tropical (MJO) effect on the associated vertical wind speed over the MT region is larger than that of extratropical drivers on MT rainfall. While previous studies that have analysed the relationships between the ISM and the mid-latitude circulation have often considered the rainfall over north-western India (Ding and Wang, 2005; Beverley et al., 2019; Stephan et al., 2019), here we take into account the MT rainfall, showing a connection between active and break phases of the ISM (by definition identified over this region; Krishnan et al., 2000) and the circumglobal teleconnection pattern. The circumglobal teleconnection pattern is an important source of variability for European summer weather, and thus improving its representation in seasonal forecasting models could in turn improve seasonal forecasts in boreal summer (which generally show lower skill than those for boreal winter) (Beverley et al., 2019). Related to the confirmed relevance of extratropical drivers for ISM variability at weekly timescales, we emphasize that there is a substantial body of literature suggesting that the influence from the mid-latitudes is particularly important for extremes (Lau and Kim, 2011; Vellore et al., 2014, 2016). Future work should therefore aim to further disentangle the specific mechanisms that particularly act in the context of extremes.

Data availability. The data used in this article can be accessed by contacting the corresponding author.

Supplement. The supplement related to this article is available online at: https://doi.org/10.5194/esd-11-17-2020-supplement.

Author contributions. GDC, DC and BvdH designed the analysis. GDC performed the analysis and wrote the first draft of the paper. All authors contributed to the interpretation of the results and to the writing of the paper.

Competing interests. The authors declare that they have no conflict of interest.

Acknowledgements. We thank the ECMWF and NCEP for making the ERA-Interim and CPC-NCEP data available. We thank the anonymous reviewers for helping us improve the content of this paper and for their encouraging words. 
Financial support. This research has been supported by the Bundesministerium für Bildung und Forschung (grant nos. 01LP1611A, 01LN1306A, and 01LN1304A) and the Nederlandse Organisatie voor Wetenschappelijk Onderzoek (grant no. 016.Vidi.171011).

The publication of this article was funded by the Open Access Fund of the Leibniz Association.

Review statement. This paper was edited by Govindasamy Bala and reviewed by two anonymous referees.

\section{References}

Anandh, P. C., Vissa, N. K., and Broderick, C.: Role of MJO in modulating rainfall characteristics observed over India in all seasons utilizing TRMM, Int. J. Climatol., 38, 2352-2373, https://doi.org/10.1002/joc.5339, 2018.

Bello, G. A., Angus, M., Pedemane, N., Harlalka, J. K., Semazzi, F. H. M., Kumar, V., and Samatova, N. F.: Response-Guided Community Detection: Application to Climate Index Discovery, in: Machine Learning and Knowledge Discovery in Databases, Springer-Verlag, Portugal, 736-751, 2015.

Benjamini, Y. and Hochberg, Y.: Controlling the False Discovery Rate: a Practical and Powerful Approach to Multiple Testing, J. R. Stat. Soc. Ser. B, 57, 289-300, https://doi.org/10.1111/j.25176161.1995.tb02031.x, 1995.

Benjamini, Y. and Yekutieli, D.: The control of the false discovery rate in multiple testing under dependency, Ann. Stat., 29, 11651188, https://doi.org/10.1214/aos/1013699998, 2001.

Beverley, J. D., Woolnough, S. J., Baker, L. H., Johnson, S. J., and Weisheimer, A.: The northern hemisphere circumglobal teleconnection in a seasonal forecast model and its relationship to European summer forecast skill, Clim. Dynam., 52, 3759-3771, https://doi.org/10.1007/s00382-018-4371-4, 2019.

Chattopadhyay, R., Goswami, B. N., Sahai, A. K., and Fraedrich, K.: Role of stratiform rainfall in modifying the northward propagation of monsoon intraseasonal oscillation, J. Geophys. Res., 114, D19114, https://doi.org/10.1029/2009JD011869, 2009.

Chen, M., Shi, W., Xie, P., Silva, V. B. S., Kousky, V. E., Higgins, R. W., and Janowiak, J. E.: Assessing objective techniques for gauge-based analyses of global daily precipitation, J. Geophys. Res.-Atmos., 113, 1-13, https://doi.org/10.1029/2007JD009132, 2008.

Cherchi, A., Annamalai, H., Masina, S., and Navarra, A.: South Asian summer monsoon and the eastern Mediterranean climate: The monsoon-desert mechanism in CMIP5 simulations, J. Climate, 27, 6877-6903, https://doi.org/10.1175/JCLI-D-13$00530.1,2014$.

Cherchi, A., Annamalai, H., Masina, S., Navarra, A., and Alessandri, A.: Twenty-first century projected summer mean climate in the Mediterranean interpreted through the monsoon-desert mechanism, Clim. Dynam., 47, 2361-2371, https://doi.org/10.1007/s00382-015-2968-4, 2016.

Choudhury, A. D. and Krishnan, R.: Dynamical Response of the South Asian Monsoon Trough to Latent Heating from Stratiform and Convective Precipitation, J. Atmos. Sci., 68, 1347-1363, https://doi.org/10.1175/2011JAS3705.1, 2011.
Dee, D. P., Uppala, S. M., Simmons, A. J., Berrisford, P., Poli, P., Kobayashi, S., Andrae, U., Balmaseda, M. A., Balsamo, G., Bauer, P., Bechtold, P., Beljaars, A. C. M., van de Berg, L., Bidlot, J., Bormann, N., Delsol, C., Dragani, R., Fuentes, M., Geer, A. J., Haimberger, L., Healy, S. B., Hersbach, H., Hólm, E. V., Isaksen, L., Kållberg, P., Köhler, M., Matricardi, M., Mcnally, A. P., Monge-Sanz, B. M., Morcrette, J. J., Park, B. K., Peubey, C., de Rosnay, P., Tavolato, C., Thépaut, J. N., and Vitart, F.: The ERA-Interim reanalysis: Configuration and performance of the data assimilation system, Q. J. Roy. Meteor. Soc., 137, 553-597, https://doi.org/10.1002/qj.828, 2011.

Di Capua, G., Kretschmer, M., Runge, J., Alessandri, A., Donner, R. V., van den Hurk, B., Vellore, R., Krishnan, R., and Coumou, D.: Long-Lead Statistical Forecasts of the Indian Summer Monsoon Rainfall Based on Causal Precursors, Weather Forecast., 34, 1377-1394, https://doi.org/10.1175/waf-d-19-0002.1, 2019.

Ding, Q. and Wang, B.: Circumglobal teleconnection in the Northern Hemisphere summer, J. Climate, 18, 3483-3505, https://doi.org/10.1175/JCLI3473.1, 2005.

Ding, Q. and Wang, B.: Intraseasonal teleconnection between the summer Eurasian wave train and the Indian Monsoon, J. Climate, 20, 3751-3767, https://doi.org/10.1175/JCLI4221.1, 2007.

Gadgil, S. and Joseph, P. V: On breaks of the Indian monsoon, Proc. Indian Acad. Sci. (Earth Planet. Sci.), 112, 529-558, https://doi.org/10.1007/BF02709778, 2003.

Goswami, B. N. and Ajaya Mohan, R. S.: Intraseasonal Oscillations and Interannual Variability of the Indian Summer Monsoon, J. Climate, 14, 1180-1198, https://doi.org/10.1007/BF02842260, 2001.

Goswami, B. N. and Xavier, P. K.: Dynamics of "internal" interannual variability of the Indian summer monsoon in a GCM, J. Geophys. Res., 110, D24104, https://doi.org/10.1029/2005JD006042, 2005.

Goswami, B. N., Madhusoodanan, M. S., Neema, C. P., and Sengupta, D.: A physical mechanism for North Atlantic SST influence on the Indian summer monsoon, Geophys. Res. Lett., 33, 1-4, https://doi.org/10.1029/2005GL024803, 2006.

Hannachi, A., Jolliffe, I. T., and Stephenson, D. B.: Empirical orthogonal functions and related techniques in atmospheric science: A review, Int. J. Climatol., 713, 697-713, https://doi.org/10.1002/joc.1499, 2007.

Kiladis, G. N., Dias, J., Straub, K. H., Wheeler, M. C., Tulich, S. N., Kikuchi, K., Weickmann, K. M., and Ventrice, M. J.: A Comparison of OLR and Circulation-Based Indices for Tracking the MJO, Mon. Weather Rev., 142, 1697-1715, https://doi.org/10.1175/MWR-D-13-00301.1, 2014.

Kretschmer, M., Coumou, D., Donges, J. F., and Runge, J.: Using Causal Effect Networks to analyze different Arctic drivers of mid-latitude winter circulation, J. Climate, 29, 4069-4081, https://doi.org/10.1175/JCLI-D-15-0654.1, 2016.

Kretschmer, M., Runge, J., and Coumou, D.: Early prediction of extreme stratospheric polar vortex states based on causal precursors, Geophys. Res. Lett., 44, 1-9, https://doi.org/10.1002/2017GL074696, 2017.

Kretschmer, M., Coumou, D., Agel, L., Barlow, M., Tziperman, E., and Cohen, J.: More-persistent weak stratospheric polar vortex States linked to cold extremes, B. Am. Meteorol. Soc., 99, 4960, https://doi.org/10.1175/BAMS-D-16-0259.1, 2018. 
Kripalani, R. H. Ã., Kulkarni, A., and Singh, S. V.: Association of the Indian summer monsoon with the northern hemisphere mid-latitude circulation, Int. J. Climatol., 17, 1055-1067, https://doi.org/10.1002/(SICI)10970088(199708)17:10<1055::AID-JOC180>3.0.CO;2-3, 1997.

Krishnamurti, T. N. and Bhalme, H. H.: Oscillations of a monsoon system Part I: Observational apects, J. Atmos. Sci., 33, 1937-1954, https://doi.org/10.1175/15200469(1976)033<1937:OOAMSP>2.0.CO;2, 1976.

Krishnamurti, T. N. and Surgi, N.: Observational aspects of the summer monsoon, in Monsoon Meteorology, edited by: Chang, C.-P. and Krishnamurti, T. N., 3-25, Oxford University Press, Oxford, UK, 1987.

Krishnan, R., Zhang, C., and Sugi, M.: Dynamics of Breaks in the Indian Summer Monsoon, J. Atmos. Sci., 57, 1354-1372, 2000.

Krishnan, R., Kumar, V., Sugi, M., and Yoshimura, J.: Internal Feedbacks from Monsoon - Midlatitude Interactions during Droughts in the Indian Summer Monsoon, J. Atmos. Sci., 66, 553-578, https://doi.org/10.1175/2008JAS2723.1, 2009.

Lau, W. K. M. and Kim, K.-M.: The 2010 Pakistan Flood and Russian Heat Wave?: Teleconnection of Hydrometeorological Extremes, J. Hydrometeorol., 13, 392-403, https://doi.org/10.1175/JHM-D-11-016.1, 2011.

Levermann, A., Schewe, J., Petoukhov, V., and Held, H.: Basic mechanism for abrupt monsoon transitions, P. Natl. Acad. Sci. USA, 106, 20572-20577, https://doi.org/10.1073/pnas.0901414106, 2009.

McGraw, M. C. and Barnes, E. A.: Memory matters: A case for granger causality in climate variability studies, J. Climate, 31, 3289-3300, https://doi.org/10.1175/JCLI-D-17-0334.1, 2018.

Mishra, S. K., Sahany, S., and Salunke, P.: Linkages between MJO and summer monsoon rainfall over India and surrounding region, Meteorol. Atmos. Phys., 129, 283-296, https://doi.org/10.1007/s00703-016-0470-0, 2017.

North, G. R., Bell, T. L., Cahalan, R. F., and Moeng, F. J.: Sampling Errors in the Estimation of empirical Orthogonal Functions, Mon. Weather Rev., 110, 699-706, https://doi.org/10.1175/15200493(1982)110<0699:SEITEO>2.0.CO;2, 1982.

Pai, D. S., Bhate, J., Sreejith, O. P., and Hatwar, H. R.: Impact of $\mathrm{MJO}$ on the intraseasonal variation of summer monsoon rainfall over India, Clim. Dynam., 36, 41-55, https://doi.org/10.1007/s00382-009-0634-4, 2011.

Pai, D. S., Latha, D. S. P., Badwaik, S. M. R., and Rajeevan, M.: Analysis of the daily rainfall events over India using a new long period (1901-2010) high resolution $\left(0.25^{\circ} \times\right.$ $0.25^{\circ}$ ) gridded rainfall data set, Clim. Dynam., 45, 755-776, https://doi.org/10.1007/s00382-014-2307-1, 2015.

Pathak, A., Ghosh, S., Kumar, P., and Murtugudde, R.: Role of Oceanic and Terrestrial Atmospheric Moisture Sources in Intraseasonal Variability of Indian Summer Monsoon Rainfall, Sci. Rep., 7, 12729, https://doi.org/10.1038/s41598-017-131157, 2017.

Rajeevan, M., Pai, D. S., Anil Kumar, R., and Lal, B.: New statistical models for long-range forecasting of southwest monsoon rainfall over India, Clim. Dynam., 28, 813-828, https://doi.org/10.1007/s00382-006-0197-6, 2007.

Rao, Y. P.: Southwest monsoon, METEOROLOG., Meteorological Monograph: Synoptic Meteorology, New Delhi, India, 1976.
Rodwell, M. J. and Hoskins, B.: Monsoons and the dynamics of deserts, Q. J. Roy. Meteor. Soc., 122, 1385-1404, 1996.

Runge, J.: Causal network reconstruction from time series?: From theoretical assumptions to practical estimation, Chaos, 28, 075310, https://doi.org/10.1063/1.5025050, 2018.

Runge, J., Petoukhov, V., and Kurths, J.: Quantifying the strength and delay of climatic interactions: The ambiguities of cross correlation and a novel measure based on graphical models, J. Climate, 27, 720-739, https://doi.org/10.1175/JCLI-D-13-00159.1, 2014.

Runge, J., Petoukhov, V., Donges, J. F., Hlinka, J., Jajcay, N., Vejmelka, M., Hartman, D., Marwan, N., Paluš, M., and Kurths, J.: Identifying causal gateways and mediators in complex spatio-temporal systems, Nat. Commun., 6, 9502, https://doi.org/10.1038/ncomms9502, 2015.

Runge, J., Nowack, P., Kretschmer, M., Flaxman, S., and Sejdinovic, D.: Detecting causal associations in large nonlinear time series datasets, Sci. Adv., 5, eaau4996, https://doi.org/10.1126/sciadv.aau4996, 2019.

Saeed, S., Müller, W. A., Hagemann, S., Jacob, D., Mujumdar, M., and Krishnan, R.: Precipitation variability over the South Asian monsoon heat low and associated teleconnections, Geophys. Res. Lett., 38, L08702, https://doi.org/10.1029/2011GL046984, 2011.

Saggioro, E. and Shepherd, T. G.: Quantifying the timescale and strength of Southern Hemisphere intra-seasonal stratospheretroposphere coupling, Geophys. Res. Lett., 46, 13479-13487, https://doi.org/10.1029/2019GL084763, 2019.

Saha, S. K., Halder, S., Suryachandra Rao, A., and Goswami, B. N.: Modulation of ISOs by land-atmosphere feedback and contribution to the interannual variability of Indian summer monsoon, J. Geophys. Res.-Atmos., 117, 1-14, https://doi.org/10.1029/2011JD017291, 2012.

Schleussner, C. F., Runge, J., Lehmann, J., and Levermann, A.: The role of the North Atlantic overturning and deep ocean for multidecadal global-mean-temperature variability, Earth Syst. Dynam., 5, 103-115, https://doi.org/10.5194/esd-5-103-2014, 2014.

Shige, S., Nakano, Y., and Yamamoto, M. K.: Role of Orography, Diurnal Cycle, and Intraseasonal Oscillation in Summer Monsoon Rainfall over the Western Ghats and Myanmar Coast, J. Climate., 30, 9365-9381, https://doi.org/10.1175/JCLI-D-160858.1, 2017.

Spirtes, P., Glymour, C., and Scheines, R.: Causation, prediction, and search, The MIT Press, Boston, USA, 2000.

Stephan, C. C., Klingaman, N. P., and Turner, A. G.: A mechanism for the interdecadal variability of the Silk Road Pattern, J. Climate, 32, 717-736, https://doi.org/10.1175/JCLI-D-18-0405.1, 2019.

Suhas, E., Neena, J. M., and Goswami, B. N.: Interannual Variability of Indian Summer Monsoon arising from Interactions between Seasonal Mean and Intraseasonal Oscillations, J. Atmos. Sci., 69, 1761-1774, https://doi.org/10.1175/JAS-D-11-0211.1, 2012.

Vellore, R. K., Krishnan, R., Pendharkar, J., Choudhury, A. D., and Sabin, T. P.: On the anomalous precipitation enhancement over the Himalayan foothills during monsoon breaks, Clim. Dynam., 43, 2009-2031, https://doi.org/10.1007/s00382-013-20241,2014 .

Vellore, R. K., Kaplan, M. L., John, R. K., Sabade, S., Deshpande, N., and Singh, B. B.: Monsoon - extratropical circulation inter- 
actions in Himalayan extreme rainfall, Clim. Dynam., 46, 35173546, https://doi.org/10.1007/s00382-015-2784-x, 2016.

Wang, B., Webster, P., Kikuchi, K., Yasunari, T., and Qi, Y.: Boreal summer quasi-monthly oscillation in the global tropics, Clim. Dynam., 16, 661-675, https://doi.org/10.1007/s00382006-0163-3, 2006.

Wang, H., Wang, B., Huang, F., Ding, Q., and Lee, J. Y.: Interdecadal change of the boreal summer circumglobal teleconnection (1958-2010), Geophys. Res. Lett., 39, 1-6, https://doi.org/10.1029/2012GL052371, 2012.

Wang, S., Ma, D., Sobel, A. H., and Tippett, M. K.: Propagation Characteristics of BSISO Indices, Geophys. Res. Lett., 45, 99349943, https://doi.org/10.1029/2018GL078321, 2018.

Webster, P. J. and Lawrence, D. M.: The Boreal Summer Intraseasonal Oscillation: Relationship between Northward and Eastward Movement of Convection, J. Atmos. Sci., 59, 1593-1606, https://doi.org/10.1175/15200469(2002)059<1593:TBSIOR>2.0.CO;2, 2002.
Wheeler, M. C. and Hendon, H. H.: An All-Season RealTime Multivariate MJO Index: Development of an Index for Monitoring and Prediction, Mon. Weather Rev., 132, 1917-1932, https://doi.org/10.1175/15200493(2004)132<1917:AARMMI>2.0.CO;2, 2004.

Wilks, D. S.: The Stippling Shows Statistically Significant Grid Points, B. Am. Meteorol. Soc., 97, 2263-2274, https://doi.org/10.1175/BAMS-D-15-00267.1, 2016.

Willink, D., Khan, V., and Donner, R. V.: Improved one-month leadtime forecasting of the SPI over Russia with pressure covariates based on the SL-AV model, Q. J. Roy. Meteor. Soc., 143, 26362649, https://doi.org/10.1002/qj.3114, 2017.

Yanai, M. and Wu, G.: Effects of the tibetan plateau, in: The Asian Monsoon, Springer Praxis Books, Springer, Berlin, Heidelberg, https://doi.org/10.1007/3-540-37722-0_13, 2006.

Zhang, C.: Madden-Julian Oscillation, Rev. Geophys., 43, RG2003, https://doi.org/10.1029/2004RG000158, 2005. 